\title{
A New Perspective on Four Decades of Changes in Arctic Sea Ice from Satellite Observations
}

\author{
Xuanji Wang ${ }^{*}$, Yinghui Liu ${ }^{2}$, Jeffrey R. Key ${ }^{2}$, and Richard Dworak ${ }^{1}$ \\ 1 Cooperative Institute for Meteorological Satellite Studies, University of Wisconsin-Madison, Madison, WI \\ 53706, USA; xuanjiwang@wisc.edu (X.W.); rdworak@ssec.wisc.edu (R.D.) \\ 2 Center for Satellite Applications and Research, NOAA/NESDIS, Madison, WI 53706, USA; ying- \\ hui.liu@noaa.gov (Y.L.); jeff.key@noaa.gov (J.K.) \\ * Correspondence: xuanjiwang@wisc.edu; Tel.: +1-608-239-8187
}

\begin{abstract}
Arctic sea ice characteristics have been changing rapidly and significantly in the last few decades. Using a long-term time series of sea ice products from satellite observations - the extended AVHRR Polar Pathfinder (APP-x), trends in sea ice concentration, ice extent, ice thickness, and ice volume in the Arctic from 1982 to 2020 are investigated. Results show that the Arctic has warmed and become less ice covered in all seasons, especially in summer and autumn. Arctic sea ice thickness has been decreasing at the rate of $-3.24 \mathrm{~cm}$ per year, resulting in about a $52 \%$ reduction in thickness from 1982 to 2020. Arctic sea ice volume has been decreasing at the rate of $-467.7 \mathrm{~km}^{3}$ per year, resulting in a volume of $10305.5 \mathrm{~km}^{3}$ in 2020 compared to $27590.4 \mathrm{~km}^{3}$ in 1982 . These trends are further examined from a new perspective. The Arctic Ocean is classified into open water, and perennial and seasonal sea ice-covered areas based on the sea ice persistence. The loss of the perennial sea ice covered area is the major factor in the total sea ice loss in all seasons. If the current rates of sea ice changes continue, the Arctic is expected to have ice-free summers by the mid-2060s.
\end{abstract}

Keywords: sea ice; Cryosphere; Arctic Ocean; Arctic sea ice change; Arctic climate change; remote sensing retrieval; satellite remote sensing; APP; APP-x; trend study

\section{Introduction}

Sea ice covers $4-6 \%$ of the earth's surface, depending on the season, the majority of which is in the Arctic. Changes in sea ice volume and extent are of great importance in understanding global climate change due to feedback mechanisms and teleconnections as well as transitions in the state of the atmosphere, ocean, land and glacial coverage. The Arctic has been experiencing significant changes closely associated with changes in the cryosphere [1,2]. Many Arctic climate change indicators showed significant Arctic warming during the past four decades [3]. There has been a significant decline of Arctic sea ice in the past two decades as observed from both satellites and in situ measurements, with record low Arctic sea ice extent during the summer of 2007 and 2012 [4-7]. The significant decline occurred after years of shrinking and thinning of the sea ice pack [8-11] resulting from increasing surface air temperature, changes in atmospheric circulation, and the icealbedo feedback [6,12-15]. The multiyear ice of the Arctic has been rapidly replaced in recent years by thinner first-year ice [16-18] that is more sensitive to changes in atmospheric and oceanic forcing [14].

The retreat of sea ice increases surface absorption of solar radiation by the ocean due to the decrease in surface albedo, resulting in further warming and retreat of the ice pack due to the ice-albedo feedback [19-21] and the associated changes in clouds [22-24], contributing to further ice decline. As a consequence of diminishing sea ice, the Arctic area north of $60^{\circ} \mathrm{N}$ has warmed at more than twice the global average since late last century $[25,26]$. Numerical models have shown that the ice-free summer Arctic Ocean may occur as early as the late 2030s using a criterion of $80 \%$ sea ice area loss, as the Arctic regional mean surface air temperature will likely increase by $8.5 \pm 2.5^{\circ} \mathrm{C}$ in winter and $3.7 \pm 0.9^{\circ} \mathrm{C}$ 
in summer by the end of this century [27]. Other studies indicate that Arctic multiyear sea ice will mostly disappear by September 2050 no matter what actions are taken now to reduce $\mathrm{CO}_{2}$ concentration in the atmosphere $[28,29]$. The same result could occur sooner than 2030 if there is no immediate reduction in anthropogenic $\mathrm{CO}_{2}$ and $\mathrm{CH}_{4}$ emissions, as suggested by models in phase six of the Coupled Model Intercomparison Project [30].

Some numerical model studies show that the simulated mean September ice thickness within the Arctic Ocean has declined from $3.7 \mathrm{~m}$ to $2.6 \mathrm{~m}$ at the rate of $-0.57 \mathrm{~m}$ per decade over the period 1987 2007 for the Arctic Ocean basin [31]. Ice thickness data from in situ and satellite observations indicated that the trend in annual mean ice thickness over the Arctic basin is $-0.58 \pm 0.07 \mathrm{~m}$ per decade over the period 2000-2012 [32]. A modelbased reconstruction of the Arctic sea ice volume over 1980-2010 shows that the ice volume decreased at the rates of $-3.8 \times 103 \mathrm{~km}^{3}$ per decade for all months and $-4.20 \times 103 \mathrm{~km}^{3}$ per decade for September only, values that are about six times larger than during the socalled 1901-1940 Early-Twentieth-Century Warming period [33]. Climate models from the World Climate Research Programme Coupled Model Intercomparison Project Phase 5 (CMIP5) as a whole tend to underestimate the rate of ice volume loss from 1979 to 2013, leading to an uncertain projection of when Arctic Ocean may become ice-free in warm season [34,35].

Based on sea ice thickness data from satellite laser altimetry (ICESat) and radar altimetry (CryoSat-2) over the relative short time periods of 2003-2008 and 2011-2015, it was discovered that Arctic sea ice experienced net depletions of roughly $4.68 \times 103 \mathrm{~km}^{3} \mathrm{during}$ autumn (October-November) and 1.46×103 km³ during spring (February-March) [36], where most of the sea ice loss was perennial ice (two or more years old). From an ice agebased sea ice volume product, Arctic sea ice volume has a decreasing trend of $-411 \mathrm{~km}^{3}$ per year from 1984 to 2018 [37]. Furthermore, it was shown that Arctic sea ice thickness change contributed at least $80 \%$ to the sea ice volume loss from November to May, and nearly $50 \%$ in August and September.

The extended Advanced Very High Resolution Radiometer (AVHRR) Polar Pathfinder Extended (APP-x) Climate Data Record (CDR) provides a long time series of products that can be used to study changes in Arctic sea ice. APP-x consists of a suite of products starting from 1982 to the present [38]. The data set was used to generate a $25 \mathrm{~km}$ spatial resolution satellite-based ice thickness time series derived with a One-dimensional Thermal-dynamic Ice Model (OTIM) for estimating sea, lake, and river ice thickness [39]. This ice thickness time series provides a consistent, long-term product with high spatial resolution to study sea ice changes over the past 40 years. In this paper we use it and a passive microwave sea ice concentration climate data record to examine changes in Arctic sea ice concentration, extent, thickness, and volume over the period 1982 2020 for the Arctic area north of $60^{\circ} \mathrm{N}$. Temporal and spatial distributions and features of the trends are presented. Furthermore, these trends are examined in a new perspective based on sea ice persistence.

The paper is organized as follows. We first introduce the satellite data used in the trend analyses in Section 2. An effective and robust statistical method is then introduced and detailed in Section 2 as well. Characteristics and trends in ice concentration, extent, thickness, and volume are investigated in Section 3. In Section 4 we present and discuss the trends and their uncertainties. Based on these trends we estimate when the Arctic Ocean may be ice free in summer.

\section{Data and Methods}

\subsection{Data Sets}

Two CDRs covering the polar regions have been produced from the AVHRR data: the AVHRR Polar Pathfinder (APP) and the Extended APP (APP-x) [38]. The APP data set consists of twice-daily composites of AVHRR sensor data at a $5 \mathrm{~km}$ pixel size over the period of 1982 to the present. APP also includes a surface type derived from the NOAA/NSIDC Passive Microwave Sea Ice Concentration (SIC) CDR 
(https://nsidc.org/data/g02202; Meier et al., 2017) along with SIC. The SIC trends presented in this study were derived from the NOAA/NSIDC CDR, which is also contained within the APP-x product output. The APP-x data set includes retrievals of cloud fraction, cloud optical depth, cloud particle phase and size, cloud top pressure and temperature, surface skin temperature, surface broadband albedo, radiation fluxes, cloud radiative effects ("cloud forcing"), and sea ice thickness retrieved with OTIM [39]. For computational considerations, the original $5 \mathrm{~km}$ APP data were subsampled to $25 \mathrm{~km}$ for the products generated in APP-x. The retrievals were done with the Cloud and Surface Parameter Retrieval (CASPR) system [40,41]. Radiation fluxes were calculated in CASPR using FluxNet [42]. The consistency of the products from different satellites in APP and APP-x has been previously studied and no significant biases were observed [15]. The APP-x data products have been validated primarily with the data collected during the Surface Heat Balance of the Arctic Ocean (SHEBA) field experiment in the western Arctic [43-45], and with the data from two Antarctic meteorological stations: South Pole and Neumayer [46]. The uncertainties of the satellite retrieved surface, cloud, and radiation properties were discussed in a previous paper by Wang and Key [47].

OTIM was developed to retrieve sea, lake, and river ice thickness [39]. The inputs of the OTIM include APP and some parameters in APP-x, e.g., ice surface temperature. The outputs are ice thickness and age as part of the APP-x product suite. The sea ice thickness in the APP-x data set has been validated extensively with the data from other satellites, aircraft, in-situ measurements, and models [39, 48].

\subsection{Methods}

The focus of this paper is on trends in sea ice concentration (SIC), sea ice extent (SIE), sea ice thickness (SIT), and sea ice volume (SIV). Sea ice extent is a measurement of the total area that is covered by ice, where each satellite pixel must have at least $15 \%$ ice. Sea ice concentration is the fractional area covered by ice in a satellite pixel, with values ranging from 0 to 1 or $0 \%$ to $100 \%$. Sea ice thickness is the depth of a sea ice slab from its bottom to the interface of the ice and its overlying snow, if present, or the ice and the atmosphere in the absence of snow. Sea ice volume is the total volume of the ice, calculated from concentration and thickness.

In this study, the Arctic area north of $60^{\circ} \mathrm{N}$ latitude (AO60) is classified into three categories based on the sea ice persistence in each satellite grid cell: seasonal ice-covered area (SICA) where sea ice exists less than $95 \%$ of the days in a year, perennial ice-covered area (PICA) where sea ice exists $95 \%$ or more of the days in a year, and open water area which has ice cover $0 \%$ of the days in a year. The all ice-covered area (AICA) is defined as the sum of SICA and PICA (Figure 1). Therefore, the term seasonal ice (SI) refers to the ice in the seasonal ice-covered area, and perennial ice (PI) refers to the ice in the perennial icecovered area. Definitions of these categories do not consider whether or not ice moves into or out of the grid cell, and no attempt is made to track ice parcels. The presence or absence of ice is determined at each location (grid cell) daily. This is unlike the ice age categories by Tschudi et al. [49], which employed Lagrangian tracking of ice parcels over long period of time to determine their age in years. It is also unlike the traditional first-year and multiyear ice types that can be determined with passive microwave data. This definition provides a new perspective in understanding changes in sea ice. It is, after all, the presence and persistence of ice in an area, not an ice parcel drifting through it, that directly influences local weather and climate, indirectly influences larger-scale climate, and impacts marine transportation and ecosystems. 

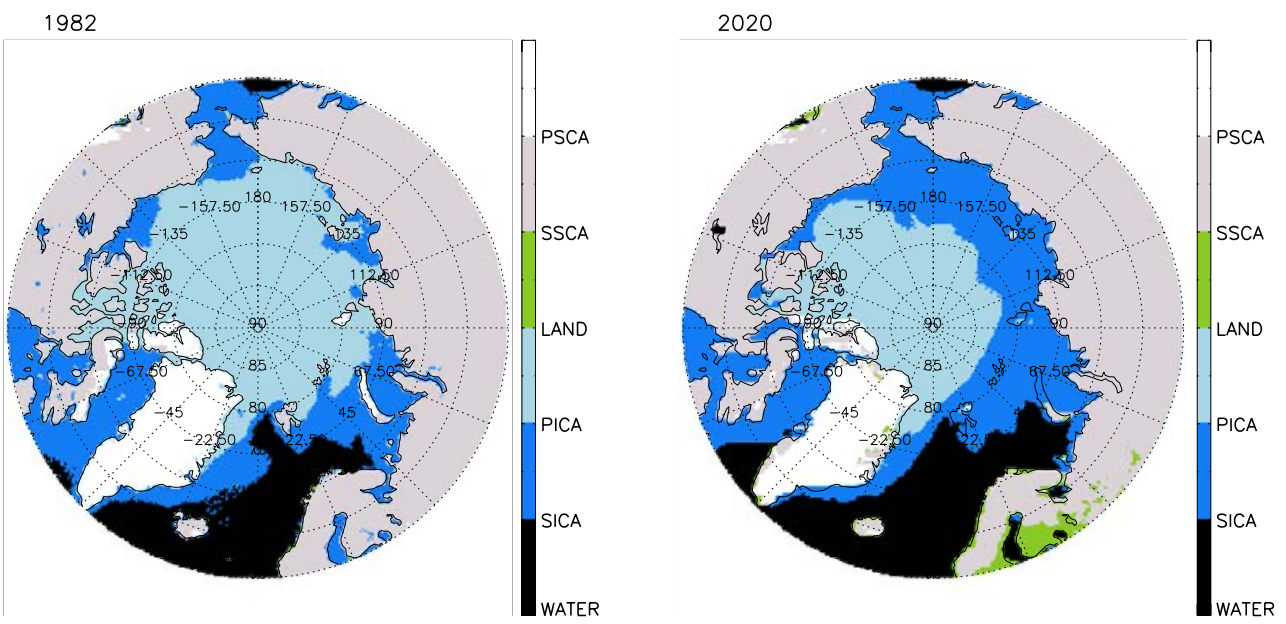

Figure 1. Spatial distribution of Arctic sea ice extent in 1982 (left) and 2020 (right) derived from NOAA/NSIDC Climate Data Record of Passive Microwave Sea Ice Concentration. Color bar notation: WATER means open water area, SICA stands for seasonal ice-covered area, PICA denotes perennial ice-covered area, LAND means snow-free land, SSCA stands for seasonal snow-covered land area, and PSCA denotes perennial snow-covered land area.

For the evaluation of trends, we used a number of statistical metrics. The Mann-Kendall (MK) trend test [50-52] and the Sen's slope statistical test [53] were employed in this study for the trend analyses of the inter-annual variability of the Arctic sea ice over the past four decades. The MK method was suggested by the World Meteorological Organization (WMO) for assessing trends in environmental data time-series [54]. The advantages of the MK trend test are that the measurements do not have to be normally distributed, and the trend, if present, does not have to be linear. Therefore, the MK is a non-parametric (distribution-free) test method to identify if a monotonic trend exists in a time series. Even though it is adversely affected by missing values and outliers in a time series, it is at a lesser degree than the least-squares regression. A monotonic upward (downward) trend means that the variable consistently increases (decreases) through time, but the trend may or may not be linear over any certain period of time. The MK test can be used to test if the slope of the linear regression line by Sen's method is different from zero.

The MK test consists of comparing each value of a time-series with the others remaining, that are always in sequential order. The number of times that the remaining terms are greater than that under analysis is counted $[55,56]$. The MK statistic is given by:

$$
S=\sum_{i=2}^{n} \sum_{j=1}^{i-1} \operatorname{sign}\left(x_{i}-x_{j}\right)
$$

where $n$ is the length of a time series, $x_{i}$ and $x_{j}$ are two generic sequential data values, and the function $\operatorname{sign}\left(x_{i}-x_{j}\right)$ assumes the following values:

$$
\operatorname{sign}\left(x_{i}-x_{j}\right)= \begin{cases}1, & \left(x_{i}-x_{j}\right)>0 \\ 0, & \left(x_{i}-x_{j}\right)=0 \\ -1, & \left(x_{i}-x_{j}\right)<0\end{cases}
$$

Let $S$ stand for the number of positive differences minus the number of negative differences found in the time series. For normally distributed data set that has no trend, the statistic $S$ should have the mean $\mathrm{E}(S)=0$ and the variance $\operatorname{Var}(S)$ as follows:

$$
\operatorname{Var}(s)=\frac{1}{18}\left[n(n-1)(2 n+5)-\sum_{p=1}^{g} t_{p}\left(t_{p}-1\right)\left(2 t_{p}+5\right)\right]
$$


where $n$ is the length of the time series, and $g$ is the number of tied groups and $t_{p}$ is the number of observations in the $p$ th tied group. Then the test statistic $Z$ is denoted by:

$$
Z= \begin{cases}\frac{s-1}{\sqrt{\operatorname{var}(S)}}, & S>0, \\ 0, & S=0, \\ \frac{S+1}{\sqrt{\operatorname{var}(S)}}, & S<0,\end{cases}
$$

If $Z>0$, it means an increasing trend, and vice versa. Given a confidence level $\alpha$, the sequential data would have a statistically significant trend if $|Z|>Z(1-\alpha / 2)$, where $Z(1-\alpha / 2)$ is the corresponding value of $\mathrm{P}=\alpha / 2$ following the standard normal distribution, or vice versa from given $|\mathrm{Z}|$ value calculated above in Eq. (4) to calculate confidence level, $\alpha$, following the standard normal distribution.

In addition, the magnitude of the trend in a time series is evaluated by a simple nonparametric procedure developed by Sen [53]. The trend is calculated by

$$
b=\operatorname{Median}\left(\frac{x_{j}-x_{i}}{j-i}\right), j>i
$$

where $b$ is Sen's slope estimate. $b>0$ indicates an upward trend in a time series. Otherwise, the data series presents a downward trend over the time period.

The uncertainty of the regression can be estimated by the standard error of the regression, $U_{y}$ :

$$
U_{y}=\sqrt{\frac{\sum_{i=1}^{n}\left(y_{i}-\hat{y}_{i}\right)}{n-2}}
$$

where $y_{i}$ and $\hat{y}_{i}$ are the original and regressed dependent variables values, respectively. Note that there are $(n-2)$ degrees of freedom in calculating $U_{y}$. We are estimating two parameters from the regression - the slope and the intercept. Therefore, the degrees of freedom should be $\mathrm{n}-2$ and we need at least three points to perform the regression analysis. That means that we are making two assumptions in this equation: 1) the sample population is the representative of the entire population, and 2) the values are the representative of the true y-values. For each assumption, we remove one degree of freedom, and our estimated standard deviation becomes larger.

The uncertainty of the slope can be estimated by the standard error or deviation of the slope, $U_{b}$ :

$$
U_{b}=\frac{U_{y}}{\sqrt{\sum_{i=1}^{n}\left(x_{i}-\underline{x}\right)^{2}}}
$$

where $x_{i}$ and $\underline{x}$ are the individual and mean independent variable values, respectively. The slope of the regression line and its uncertainty are obviously important, as they determine the rate and uncertainty at which the dependent variable $y$ changes with the independent variable $x$.

The uncertainty of the intercept can also be calculated in terms of the standard error of the regression as the standard error (or deviation) of the intercept, $U_{a}$ :

$$
U_{a}=U_{y} \sqrt{\frac{\sum_{i=1}^{n} x_{i}^{2}}{n \sum_{i=1}^{n}\left(x_{i}-\underline{x}\right)^{2}}}
$$


The intercept of the regression line and its uncertainty have implications for both the smallest detectable dependent variable $y$ and the corresponding lowest detectable independent variable $x$ with their uncertainty.

\section{Results}

Changing Arctic sea ice extent is one important climate factor. Per the definitions above, the SICA, PICA, and AICA do not change during a year. The SICA and PICA are not constant from 1982 to 2020. With the dramatic decrease in the overall Arctic sea ice extent, the SICA increases and PICA decreases. The time series of annual SICA, PICA, and AICA from 1982 to 2020 are shown in Figure 2.

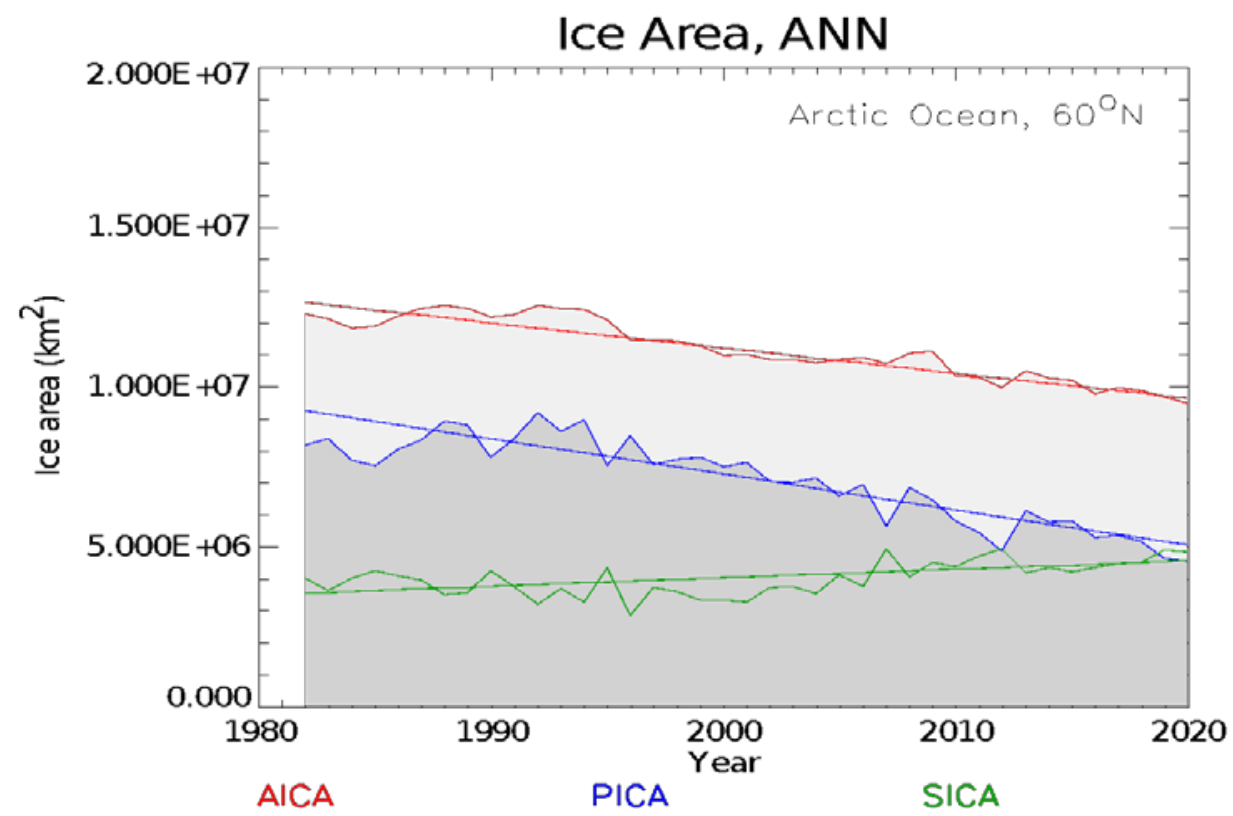

Figure 2. Time series of Arctic seasonal, perennial, and all ice-covered areas on a yearly ("ANN") basis within the Arctic area north of $60^{\circ} \mathrm{N}$ degree. SICA (green) stands for seasonal ice-covered area, PICA (blue) denotes perennial ice-covered area, and AICA (red) is the sum of SICA and PICA.

\subsection{Sea Ice Extent}

Though PICA, SICA, and AICA do not change during a year, SIE varies over the course of a year over those areas, especially for SICA. Trends need to be examined for each month. SIE in each month and monthly trends over the period 1982 2020 were calculated for PICA, SICA, and AICA.

SIE over PICA shows no monthly/seasonal changes in a year, while SIE over SICA does have monthly and seasonal fluctuations (Figure 3). SIE over PICA shows no seasonal changes by the definition of PICA, but it does have annual changes. The trends of SIE over PICA from 1982 to 2020 are approximately $-1.1 \times 105 \mathrm{~km}^{2}$ per year. SIE over SICA reaches its maximum in winter and minimum in summer. The SIE over SICA in September is not zero because of much less seasonal sea ice in early September and new seasonal sea ice forming in late September. The trends of SIE over SICA in winter are positive because of the transitions of PICA to SICA compensating the partial loss of SICA over the study period, while in summer the trends are either smaller or even negative. 

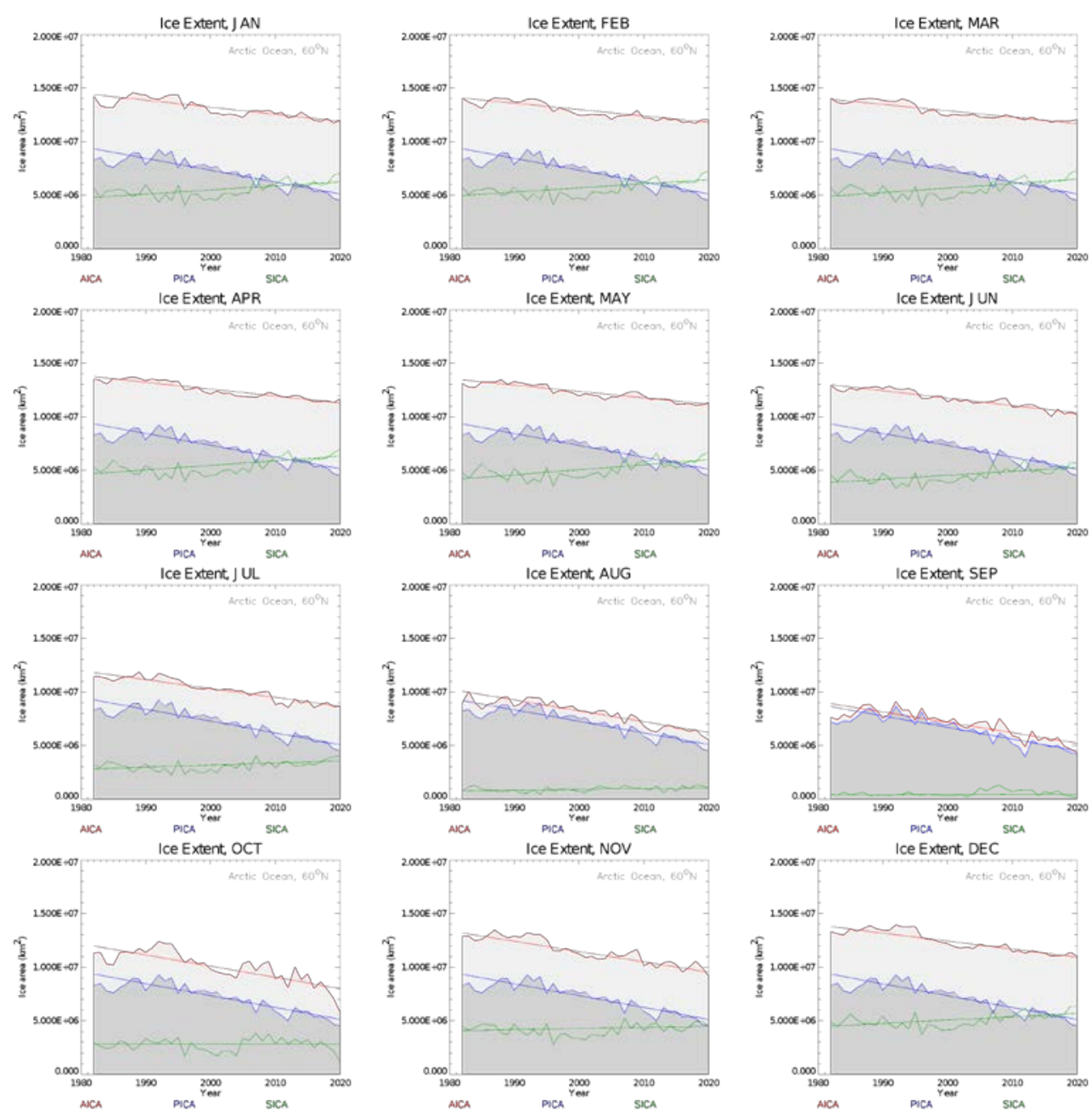

Figure 3. SIE time series for the Arctic area north of $60^{\circ} \mathrm{N}$ over $1982 \sim 2020$ for the months of January through December. PICA (blue) stands for perennial ice-covered area, SICA (green) denotes seasonal ice-covered area, and AICA (red) designates all ice (PICA + SICA) covered area.

As a combined result, the SIE over AICA in March declined to $1.21076 \times 107 \mathrm{~km}^{2}$ in 2020 from $1.41279 \times 107 \mathrm{~km}^{2}$ in 1982 , resulting in a $14 \%$ decrease at the rate of $-5.947 \times 104$ $\mathrm{km}^{2}$ per year (Table 1). In September, the SIE over AICA is 4.32892x106 km² in 2020, down from $7.63860 \times 106 \mathrm{~km}^{2}$ in 1982 , resulting in about $43 \%$ decrease at the rate of $-9.719 \times 104$ $\mathrm{km}^{2}$ per year when the ice retreats most, indicating more rapid ice area loss in summer. On an annual average, AICA SIE decreased by $2.80891 \times 106 \mathrm{~km}^{2}$ or about $22 \%$ from $1.22837 \times 107 \mathrm{~km}^{2}$ in 1982 to $9.47483 \times 106 \mathrm{~km}^{2}$ in 2020 . This overall decrease is mostly attributed to the PICA SIE reduction at $-3.64707 \times 106 \mathrm{~km}^{2}$, accounting for about $45 \%$ of PICA SIE in 1982, which is offset about $23 \%$ by SICA SIE increase during the same period (Table 1). Some of PICA SIE reduction involves the transition from PICA to SICA from 1982 to 2020.

Obviously, September had the least ice-covered areas, and exhibited decreasing trends for either of AICA and PICA to the greatest degree over $1982 \sim 2020$, though the SICA SIE trend in September is not statistically significant as in October or November. If the current SIE trend over PICA continues, the summertime ice-free Arctic Ocean would be expected in the year 2062. With the uncertainties of PICA trends for one, two, and three standard deviations, the Arctic ice-free September would be expected in 2055, 2050, and 2045 at the earliest, and in 2068, 2077, and 2088 at the latest, respectively. 
Table 1. Monthly mean SIE trends $\left(\mathrm{km}^{2}\right.$ per year) with their uncertainties and confidence levels for the Arctic area north of $60^{\circ} \mathrm{N}$ for all three categories of ice-covered areas.

\begin{tabular}{cccccccccc}
\hline \multirow{2}{*}{ Month } & \multicolumn{3}{c}{ AICA } & \multicolumn{2}{c}{ PICA } & \multicolumn{2}{c}{ SICA } \\
\cline { 2 - 9 } & $\mathbf{b}$ & $\mathbf{U b}$ & $\boldsymbol{\alpha}$ & $\mathbf{b}$ & $\mathbf{U b}$ & $\boldsymbol{\alpha}$ & $\mathbf{b}$ & $\mathbf{U}$ & $\boldsymbol{\alpha}$ \\
\hline $\mathbf{1}$ & $-6.567 \mathrm{E}+04$ & 6696. & $<0.001$ & $-1.106 \mathrm{E}+05$ & 8867. & $<0.001$ & $3.818 \mathrm{E}+04$ & 8514. & $<0.001$ \\
\hline $\mathbf{2}$ & $-5.985 \mathrm{E}+04$ & 4998. & $<0.001$ & $-1.106 \mathrm{E}+05$ & 8867. & $<0.001$ & $3.875 \mathrm{E}+04$ & 8531. & $<0.001$ \\
\hline $\mathbf{3}$ & $-5.947 \mathrm{E}+04$ & 4420. & $<0.001$ & $-1.106 \mathrm{E}+05$ & 8866. & $<0.001$ & $4.189 \mathrm{E}+04$ & 8983. & $<0.001$ \\
\hline $\mathbf{4}$ & $-6.391 \mathrm{E}+04$ & 3972. & $<0.001$ & $-1.102 \mathrm{E}+05$ & 8852. & $<0.001$ & $4.283 \mathrm{E}+04$ & 8965. & $<0.001$ \\
\hline $\mathbf{5}$ & $-5.965 \mathrm{E}+04$ & 4190. & $<0.001$ & $-1.106 \mathrm{E}+05$ & 8860. & $<0.001$ & $4.730 \mathrm{E}+04$ & 8828. & $<0.001$ \\
\hline $\mathbf{6}$ & $-6.903 \mathrm{E}+04$ & 4116. & $<0.001$ & $-1.106 \mathrm{E}+05$ & 8842. & $<0.001$ & $3.676 \mathrm{E}+04$ & 7925. & $<0.001$ \\
\hline $\mathbf{7}$ & $-8.266 \mathrm{E}+04$ & 5088. & $<0.001$ & $-1.099 \mathrm{E}+05$ & 8676. & $<0.001$ & $1.995 \mathrm{E}+04$ & 6258. & 0.010 \\
\hline $\mathbf{8}$ & $-1.011 \mathrm{E}+05$ & 7237. & $<0.001$ & $-1.076 \mathrm{E}+05$ & 8465. & $<0.001$ & 7415. & 3035. & 0.015 \\
\hline $\mathbf{9}$ & $-9.719 \mathrm{E}+04$ & 9126. & $<0.001$ & $-1.085 \mathrm{E}+05$ & 9074. & $<0.001$ & 2030. & 3973. & 0.514 \\
\hline $\mathbf{1 0}$ & $-1.042 \mathrm{E}+05$ & $1.237 \mathrm{E}+04$ & $<0.001$ & $-1.111 \mathrm{E}+05$ & 8829. & $<0.001$ & -457.0 & 8698. & 0.933 \\
\hline $\mathbf{1 1}$ & $-9.620 \mathrm{E}+04$ & 7156. & $<0.001$ & $-1.106 \mathrm{E}+05$ & 8863. & $<0.001$ & $1.022 \mathrm{E}+04$ & 8159. & 0.250 \\
\hline $\mathbf{1 2}$ & $-7.481 \mathrm{E}+04$ & 5849. & $<0.001$ & $-1.106 \mathrm{E}+05$ & 8863. & $<0.001$ & $3.314 \mathrm{E}+04$ & 8096. & 0.002 \\
\hline Annual & $-7.871 \mathrm{E}+04$ & 4800. & $<0.001$ & $-1.105 \mathrm{E}+05$ & 8739. & $<0.001$ & $2.640 \mathrm{E}+04$ & 6365. & $<0.001$ \\
\hline
\end{tabular}

For the entire Arctic area north of $60^{\circ} \mathrm{N}$, AICA SIE trends in all months and in the annual mean are mainly controlled by PICA SIE trends, suggesting the diminishing Arctic sea ice extent can mainly be attributed to the decreasing PICA year by year, e.g., the transition from PICA to SICA over the study period (Figure 3) together with the loss of SICA over the years. In addition, the ratios of PICA SIE and SICA SIE to AICA SIE are declining in March when the Arctic sea ice covered area reaches its maximum each year (Figure 4). Around 2015 SICA SIE began consistently surpassing PICA SIE.

\section{Ice Extent, MAR}

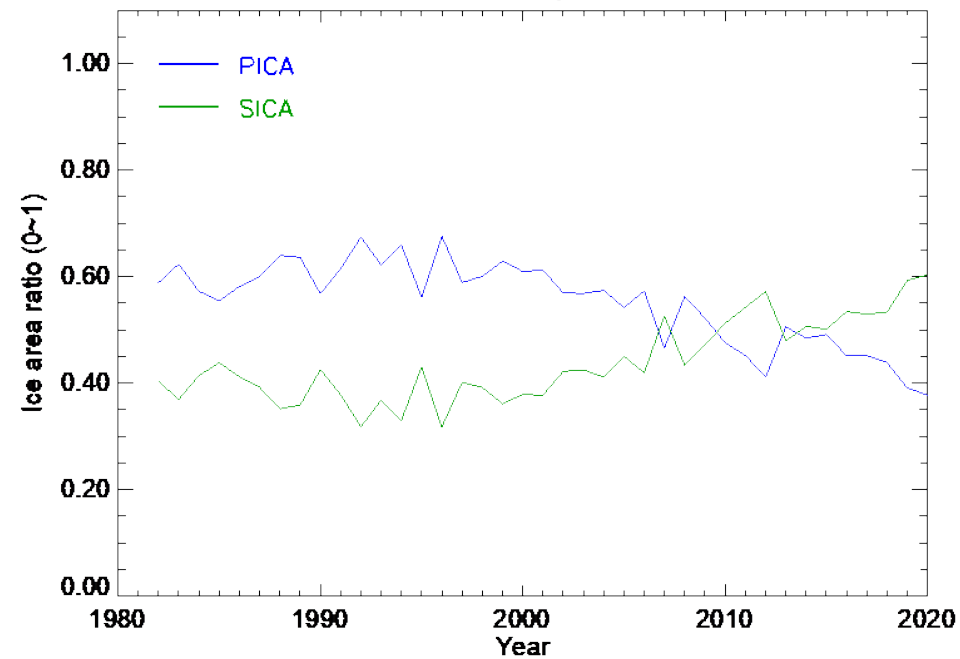

Figure 4. The ratios of PICA SIE and SICA SIE to AICA SIE in March over 1982 2020 for the Arctic Ocean area north of $60^{\circ} \mathrm{N}$.

\subsection{Sea Ice Concentration}

An example of sea ice concentration from the NOAA/NSIDC Climate Data Record of Passive Microwave Sea Ice Concentration is shown in Figure 5. The trends and patterns of SIC are determined for SICA, PICA, and AICA. Areas with SIC of $0 \%$, i.e., water pixels, were not included in the calculation of the areal mean SIC over SICA, PICA, or AICA.

Arctic SIC was changing over $1982 \sim 2020$, with the changing rates or trends that differed spatially and temporarily (Figure 6). Arctic SIC showed decreasing trends over most of the Arctic Ocean in all months, though their magnitudes were different. The largest declining trends were found in August and September over the Chukchi Sea, Beaufort Sea, Laptev Sea, Kara Sea, and Barents Sea with the biggest rate of about $-3.5 \%$ per year. 
The SIC over the Greenland Sea, Barents Sea, and Baffin Bay in winter was declining at the rate of about $-2.0 \%$ per year.
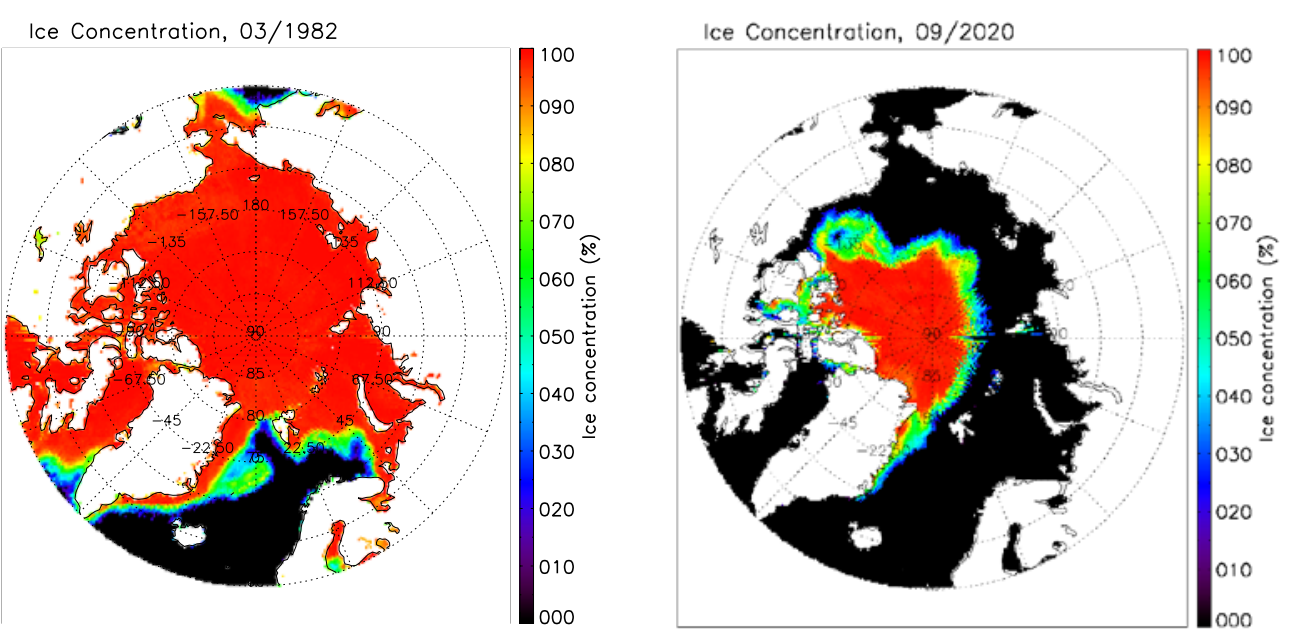

Figure 5. Spatial distribution of Arctic monthly mean SIC in March (left) and September (right) in 2020 from the NOAA/NSIDC Climate Data Record of Passive Microwave Sea Ice Concentration.

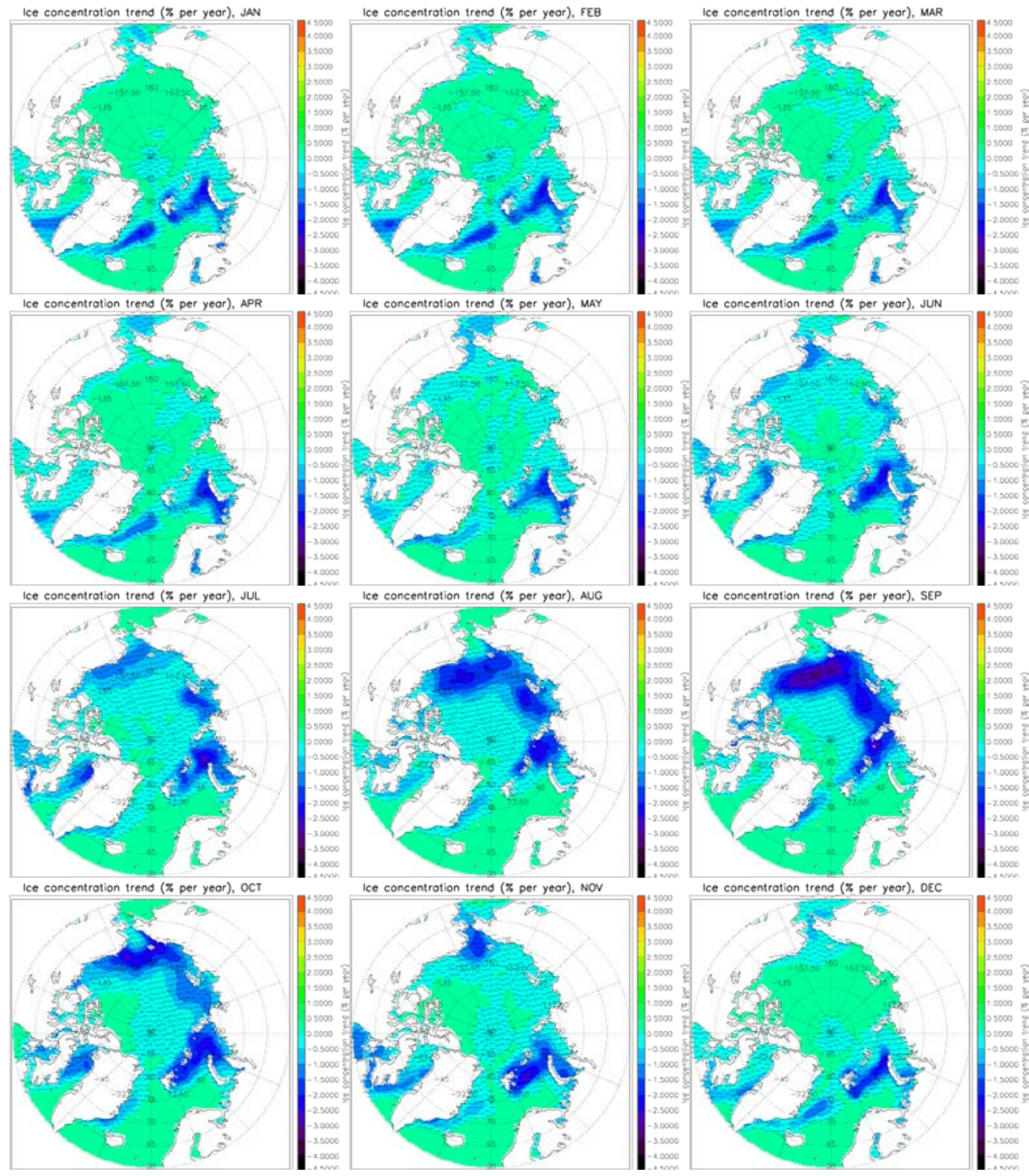

Figure 6. Spatial distributions of Arctic monthly mean SIC trends for the months of January through December over 1982 2020. The SIC decreasing areas are marked with minus signs. 
The areal mean trends in SIC were calculated for each month for PICA and SICA (Table 2). In addition, the actual fraction of the ice-covered portion in the whole Arctic area north of $60^{\circ} \mathrm{N}$ including water and ice was also calculated, called Arctic Ocean Ice Fraction (AOIF), that has a value ranging from $0 \sim 100 \%$ too.

Table 2. Monthly mean SIC trends (\% per year) with their uncertainties and confidence levels from $Z$ values for AOIF, PICA, and SICA.

\begin{tabular}{cccccccccc}
\hline \multirow{2}{*}{ Month } & \multicolumn{3}{c}{ AOIF } & \multicolumn{3}{c}{ PICA } & \multicolumn{2}{c}{ SICA } \\
\cline { 2 - 9 } & $\boldsymbol{b}$ & $\boldsymbol{U}_{\boldsymbol{b}}$ & $\boldsymbol{\alpha}$ & $\boldsymbol{b}$ & $\boldsymbol{U}_{\boldsymbol{b}}$ & $\boldsymbol{\alpha}$ & $\boldsymbol{b}$ & $\boldsymbol{\boldsymbol { U } _ { b }}$ \\
\hline $\mathbf{1}$ & -0.2243 & 0.0155 & $<0.001$ & 0.0250 & 0.0086 & $<0.001$ & 0.0921 & 0.0430 \\
\hline $\mathbf{2}$ & -0.2093 & 0.0175 & $<0.001$ & 0.0258 & 0.0053 & $<0.001$ & 0.0750 & 0.0309 & 0.062 \\
\hline $\mathbf{3}$ & -0.1809 & 0.0135 & $<0.001$ & 0.0300 & 0.0039 & $<0.001$ & 0.0875 & 0.0260 & $<0.001$ \\
\hline $\mathbf{4}$ & -0.1894 & 0.0142 & $<0.001$ & 0.0300 & 0.0055 & $<0.001$ & 0.0967 & 0.0292 & 0.003 \\
\hline $\mathbf{5}$ & -0.2255 & 0.0174 & $<0.001$ & 0.0350 & 0.0097 & $<0.001$ & 0.0217 & 0.0444 & 0.699 \\
\hline $\mathbf{6}$ & -0.3075 & 0.0182 & $<0.001$ & 0.0600 & 0.0174 & 0.003 & -0.0296 & 0.0660 & 0.735 \\
\hline $\mathbf{7}$ & -0.3850 & 0.0223 & $<0.001$ & 0.0985 & 0.0279 & 0.006 & -0.0204 & 0.0683 & 0.799 \\
\hline $\mathbf{8}$ & -0.4815 & 0.0333 & $<0.001$ & -0.0991 & 0.0458 & 0.095 & -0.0957 & 0.0903 & 0.545 \\
\hline $\mathbf{9}$ & -0.5155 & 0.0443 & $<0.001$ & -0.1221 & 0.0574 & 0.014 & -0.5833 & 0.1162 & $<0.001$ \\
\hline $\mathbf{1 0}$ & -0.4427 & 0.0374 & $<0.001$ & -0.0011 & 0.0313 & 0.952 & -0.0142 & 0.1097 & 0.828 \\
\hline $\mathbf{1 1}$ & -0.3273 & 0.0241 & $<0.001$ & 0.0363 & 0.0131 & $<0.001$ & 0.2043 & 0.0840 & $<0.001$ \\
\hline $\mathbf{1 2}$ & -0.2367 & 0.0248 & $<0.001$ & 0.0287 & 0.0118 & $<0.001$ & 0.1814 & 0.0568 & $<0.001$ \\
\hline Annual & -0.3127 & 0.0159 & $<0.001$ & 0.0194 & 0.0158 & 03454 & 0.0307 & 0.0489 & 0.809 \\
\hline
\end{tabular}

AOIF was declining due to the shrinking ice-covered areas in all months. The SIC trends over PICA and SICA were positive in the cold season (November through April), indicating that the PICA and SICA SICs were increasing. The decrease of AOIF is mainly due to losing sea ice over years. Over 1982 2020 AOIF declined to $72 \%$ from $78 \%$ in March when Arctic sea ice area is at its maximum of a year, and to $23 \%$ from $42 \%$ in September when Arctic sea ice area is at its minimum and retreats most, indicating more rapid ice loss in summer. September SIC trends are all negative and statistically significant over PICA and SICA. On an annual average, AOIF decreased to 53\% in 2020 from 66\% in 1982 at the changing rate of about $-3.13 \%$ per decade.

Figure 7 shows the SIC times series of 12 months over $1982 \sim 2020$ for AOIF, PICA, and SICA. The AOIF trends are all negative indicating the decreasing ice-covered areas in all months with the confidence level of less than 0.001 . The SIC trends over SICA are positive in the cold season (November through April) and negative in the warm season (May through October), though not statistically significant for most months. This indicates that a portion of PICA was transitioned to SICA over the years, leading to an increase in SICA. Obviously, the Arctic Ocean had the least ice-covered area in September, and exhibited decreasing trends for all of the AOIF, PICA, and SICA to the greatest degree. If the current AOIF trend continues, the summertime ice free Arctic Ocean would be expected in the year 2061 based on the AOIF decreasing at the rate of $-3 \%$ per year. With the uncertainties of AOIF trends for one, two, and three standard deviations, the ice-free September would be expected in 2054, 2049, and 2044 at the earliest, and in 2068, 2077, and 2088 at the latest, correspondingly. 

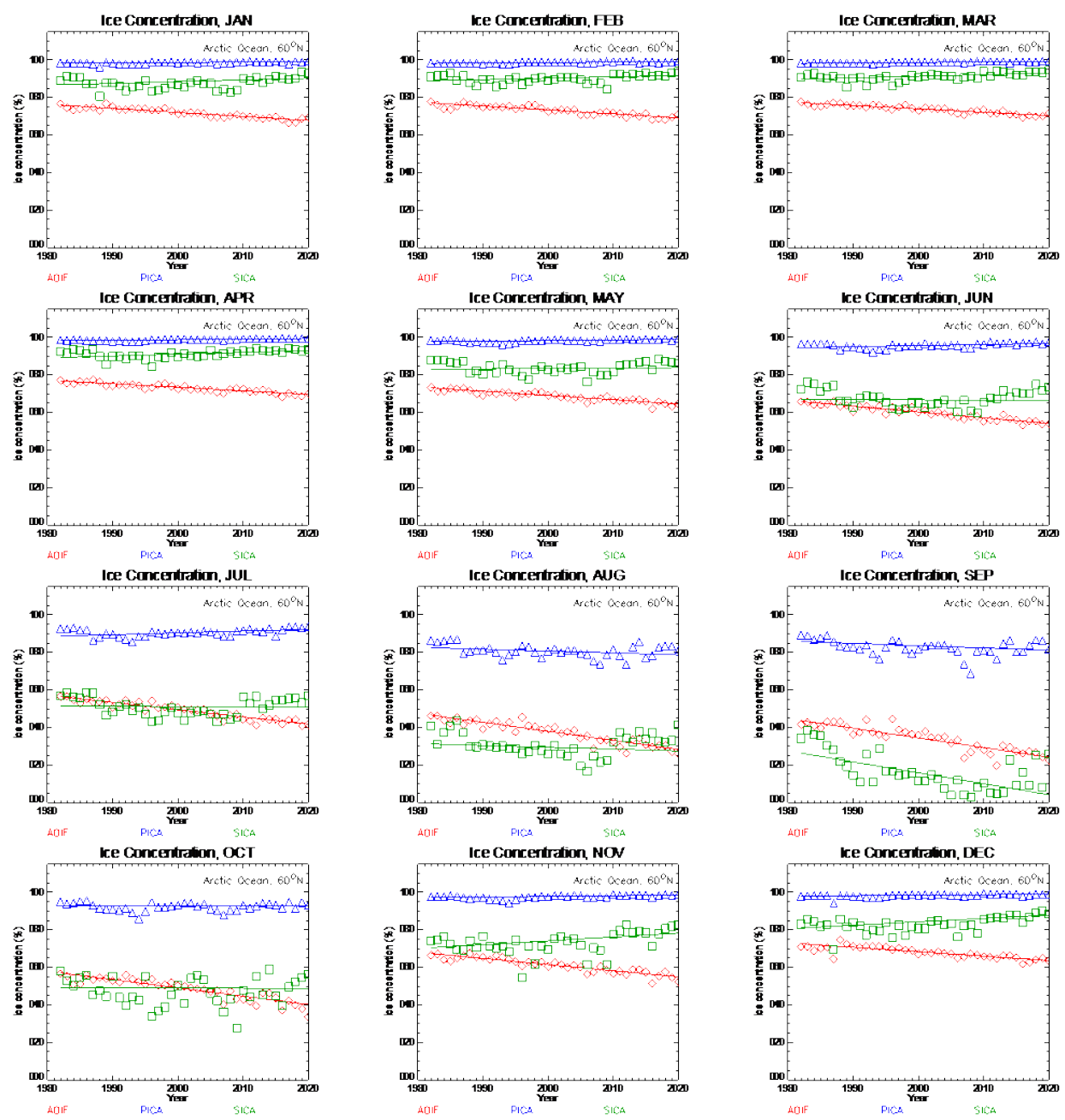

Figure 7. The SIC time series for the Arctic area north of $60^{\circ} \mathrm{N}$ over $1982 \sim 2020$ for the months of January through December. PICA (blue) stands for Perennial Ice-Covered Area, SICA (green) denotes Seasonal Ice-Covered Area, and AOIF (red) is the actual fraction of ice covered portion over the Arctic area north of $60^{\circ} \mathrm{N}$.

\subsection{Sea Ice Thickness}

Arctic Sea Ice Thickness (SIT) is not distributed evenly in space and time due to ice thermal and physical dynamic processes. The heterogeneous distribution features of SIT are apparent in the Arctic SIT distribution over the Arctic Ocean in March and September in 2020, corresponding to the maximum and minimum monthly mean SIT in a year (Figure 8). 
Ice Thickness, 03/2020

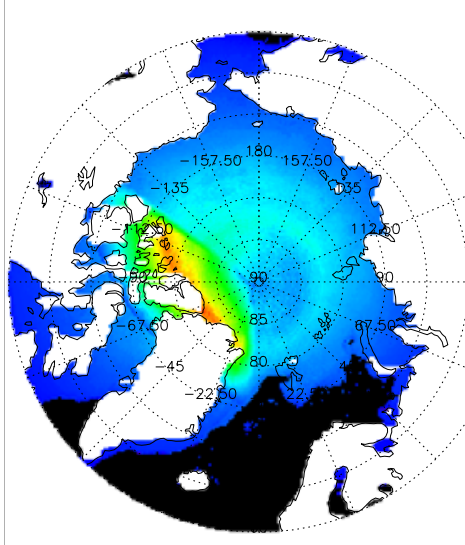

Ice Thickness, 09/2020

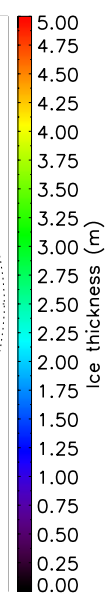

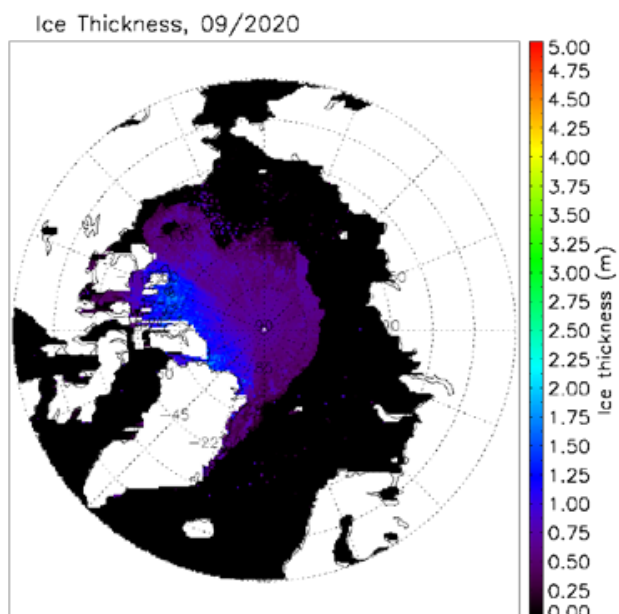

Figure 8. Spatial distributions of Arctic monthly mean SIT in March (left) and September (right) in 2020 from this study.

The AICA SIT in March decreased to $1.80 \mathrm{~m}$ in 2020 from $3.85 \mathrm{~m}$ in 1982, resulting in about $53 \%$ decrease at the rate of $-0.058 \mathrm{~m}$ per year when Arctic sea ice reaches its seasonal maximum extent in the Arctic Ocean. In September when Arctic sea ice is at its minimum extent, the AICA SIT declined to $0.71 \mathrm{~m}$ in 2020 from $1.36 \mathrm{~m}$ in 1982, resulting in about $48 \%$ decrease at the rate of $-0.016 \mathrm{~m}$ per year. On an annual average, the AICA SIT decreased by $1.22 \mathrm{~m}$ that is about $52 \%$ of $2.35 \mathrm{~m}$ in 1982, resulting in $1.13 \mathrm{~m}$ in 2020 . Both PICA and SICA SIT was declining to $1.32 \mathrm{~m}$ and $0.96 \mathrm{~m}$ in 2020 from $2.55 \mathrm{~m}$ and $1.86 \mathrm{~m}$ in 1982, respectively. All of the Arctic SIT trends in all months are statistically significant, except that SICA SIT trend in September is slightly positive with the confidence level of 0.496 due to the very small sample size of seasonal ice in September (Table 3).

Table 3. Monthly mean SIT trends (m per year) with their uncertainties and confidence levels for AICA, PICA, and SICA.

\begin{tabular}{c|c|c|c|c|c|c|c|c|c}
\hline \multirow{2}{*}{ Month } & \multicolumn{4}{|c}{ AICA } & \multicolumn{3}{c}{ PICA } & \multicolumn{3}{c}{ SICA } \\
\cline { 2 - 12 } & $\mathbf{b}$ & $\mathbf{U}$ & $\boldsymbol{\alpha}$ & $\mathbf{b}$ & $\mathbf{U}_{\mathbf{b}}$ & $\boldsymbol{\alpha}$ & $\mathbf{b}$ & $\mathbf{U}_{\mathbf{b}}$ & $\boldsymbol{\alpha}$ \\
\hline $\mathbf{1}$ & -0.0462 & 0.0012 & $<0.001$ & -0.0500 & 0.0016 & $<0.001$ & -0.0343 & 0.0012 & $<0.001$ \\
\hline $\mathbf{2}$ & -0.0513 & 0.0012 & $<0.001$ & -0.0546 & 0.0015 & $<0.001$ & -0.0378 & 0.0011 & $<0.001$ \\
\hline $\mathbf{3}$ & -0.0578 & 0.0008 & $<0.001$ & -0.0614 & 0.0012 & $<0.001$ & -0.0450 & 0.0011 & $<0.001$ \\
\hline $\mathbf{4}$ & -0.0433 & 0.0006 & $<0.001$ & -0.0282 & 0.0006 & $<0.001$ & -0.0422 & 0.0010 & $<0.001$ \\
\hline $\mathbf{5}$ & -0.0267 & 0.0003 & $<0.001$ & -0.0271 & 0.0006 & $<0.001$ & -0.0211 & 0.0005 & $<0.001$ \\
\hline $\mathbf{6}$ & -0.0219 & 0.0002 & $<0.001$ & -0.0212 & 0.0004 & $<0.001$ & -0.0177 & 0.0003 & $<0.001$ \\
\hline $\mathbf{7}$ & -0.0170 & 0.0001 & $<0.001$ & -0.0167 & 0.0002 & $<0.001$ & -0.0143 & 0.0002 & $<0.001$ \\
\hline $\mathbf{8}$ & -0.0144 & 0.0003 & $<0.001$ & -0.0144 & 0.0003 & $<0.001$ & -0.0106 & 0.0003 & $<0.001$ \\
\hline $\mathbf{9}$ & -0.0157 & 0.0012 & $<0.001$ & -0.0158 & 0.0013 & $<0.001$ & 0.0009 & 0.0015 & 0.496 \\
\hline $\mathbf{1 0}$ & -0.0243 & 0.0008 & $<0.001$ & -0.0253 & 0.0009 & $<0.001$ & -0.0159 & 0.0009 & $<0.001$ \\
\hline $\mathbf{1 1}$ & -0.0312 & 0.0010 & $<0.001$ & -0.0330 & 0.0013 & $<0.001$ & -0.0211 & 0.0011 & $<0.001$ \\
\hline $\mathbf{1 2}$ & -0.0383 & 0.0011 & $<0.001$ & -0.0406 & 0.0014 & $<0.001$ & -0.0267 & 0.0011 & $<0.001$ \\
\hline Annual & -0.0324 & 0.0004 & $<0.001$ & -0.0332 & 0.0005 & $<0.001$ & -0.0238 & 0.0005 & $<0.001$ \\
\hline
\end{tabular}


Arctic SIT decreasing trends differ in spatial and temporal domains (Figure 9). The biggest declining SIT trends occurred in February and March along the Canadian Archipelagos with the rate of about $-0.10 \mathrm{~m}$ per year, and the central Arctic Ocean contributed most to the declining SIT in AO60. The minimum declining SIT trends happened in summer from July through September with the rates ranging from -0.01 to $-0.05 \mathrm{~m}$ per year.

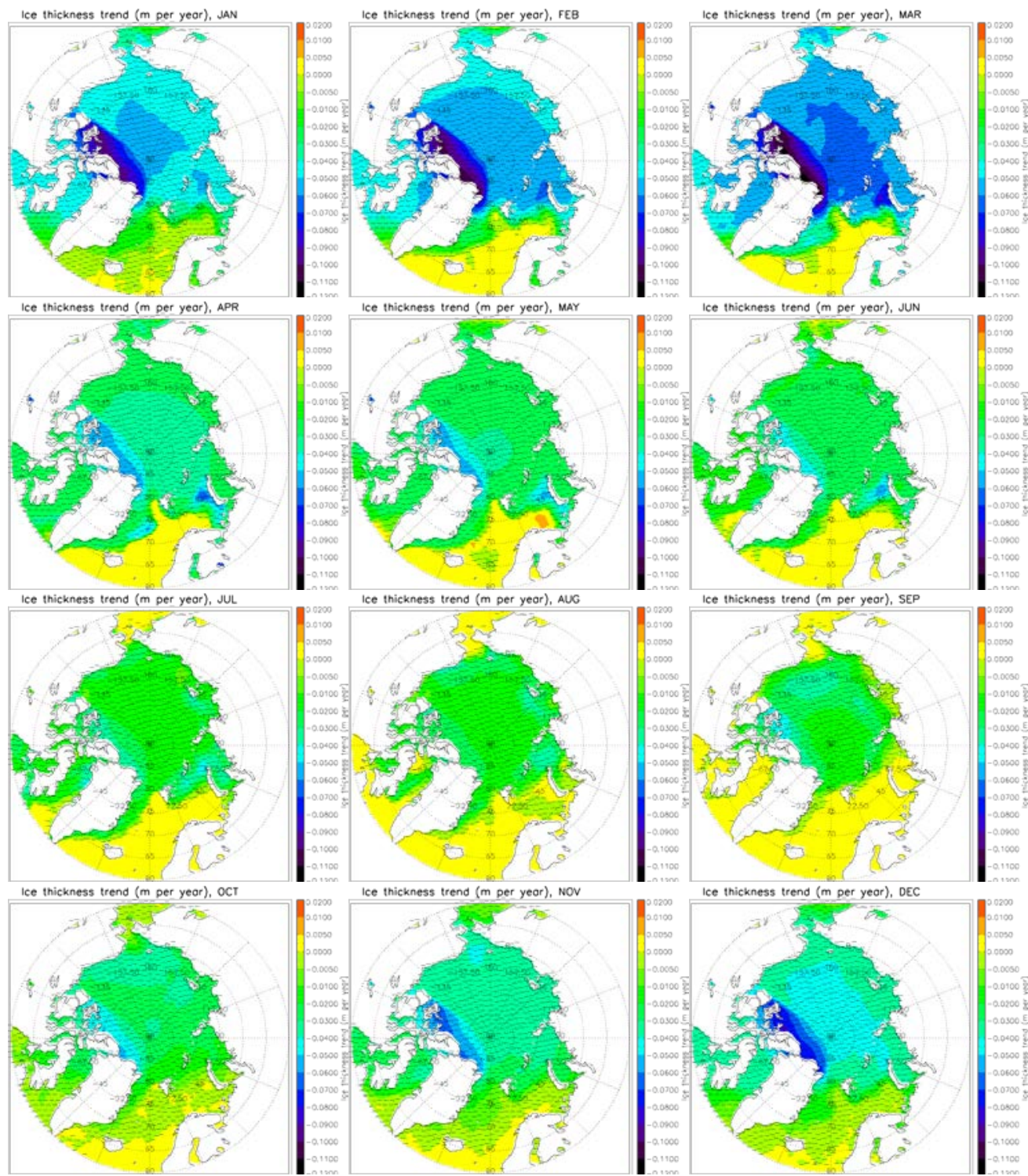

Figure 9. Spatial distributions of the Arctic monthly mean SIT trends over $1982 \sim 2020$ for the months of January through December.

The maximum SIT declining rates are $-0.058,-0.061$, and $-0.045 \mathrm{~m}$ per year in March for AICA, PICA, and SICA, respectively. In general, the Arctic SIT in Summer (July, August, and September) has the minimum changing rate of $-0.011 \sim-0.017 \mathrm{~m}$ per year for all the ice-covered areas. If the SIT over AICA and PICA continues changing at their current rates with $5 \mathrm{~cm}$ SIT as a threshold value of ice from open water, the summertime ice free Arctic Ocean would be expected in 2064 in terms of both AICA and PICA SIT with high confidence. This agrees well with the summertime ice free Arctic Ocean estimations from SIC and SIE trends analysis. With the uncertainties of the AICA and PICA SIT trends for one, two, and three standard deviations, the ice-free September would be expected in 
2058, 2052, and 2048 at the earliest, and in 2071, 2080, and 2090 at the latest, correspondingly, which also agree quite well with the previous SIC and SIE trends analysis.

It appears that AICA SIT trends are mainly controlled by PICA SIT trends (Figure 10). The sea ice in SICA may still exist in September because some sea ice in SICA can survive in the beginning of September, and some may form in the late September.

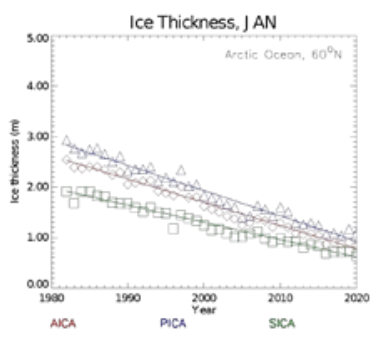

$$
\text { Ice Thickness, APR }
$$

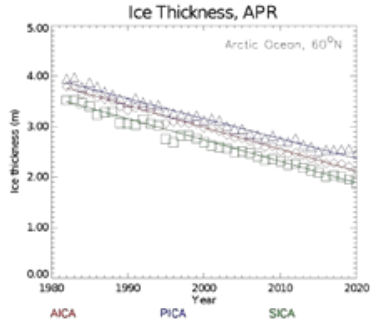

$$
\text { Ice Thickness, JUL }
$$

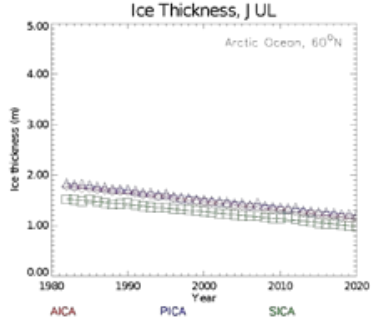

Ice Thickness, OCT

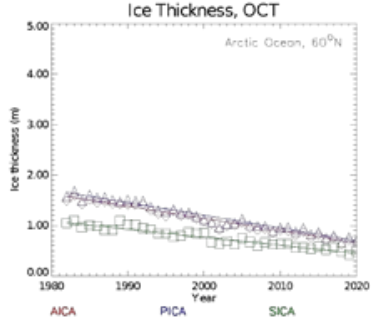

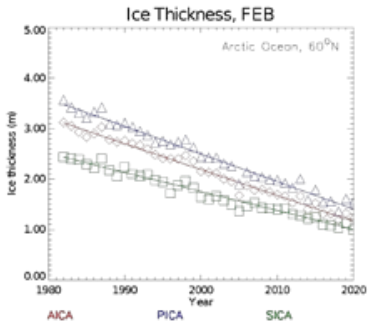

$$
\text { Ice Thickness, MAY }
$$

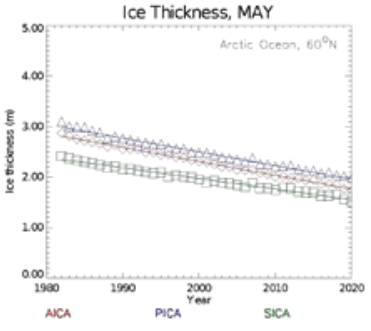

$$
\text { Ice Thickness, AUG }
$$

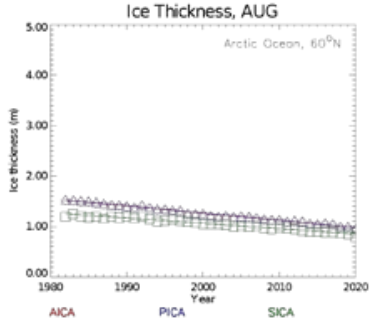

Ice Thickness, NOV

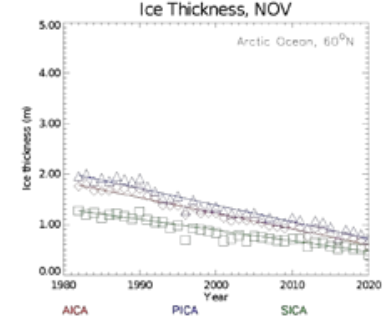

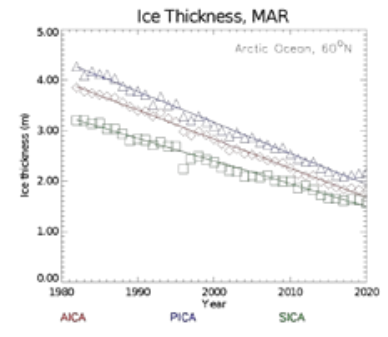

Ice Thickness, J UN

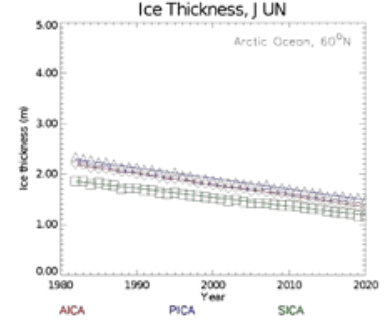

Ice Thickness, SEP

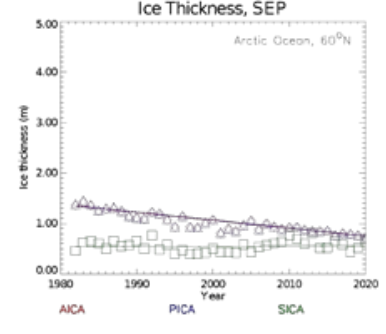

Ice Thickness, DEC

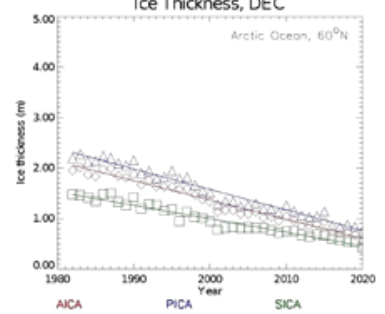

Figure 10. SIT time series for the Arctic area north of $60^{\circ} \mathrm{N}$ over $1982 \sim 2020$ for the months of January through December. PICA (blue) stands for perennial ice-covered area, SICA (green) denotes seasonal ice-covered area, and AICA (red) designates all ice (PI + SI) covered areas.

\subsection{Sea Ice Thickness}

With Arctic sea ice concentration, sea ice extent, and sea ice thickness information available, Arctic Sea Ice Volume (SIV) can be calculated as a function of ice thickness, ice extent, and ice concentration by Eq. 9 below

$$
V=H * A * C
$$

where $V$ is ice volume in $\mathrm{km}^{3}, H$ is ice thickness in $\mathrm{km}, A$ is ice extent in $\mathrm{km}^{2}, C$ is ice concentration that is unitless with a value between 0 and 1 .

As for SIT analysis above, the Arctic SIV within the Arctic area north of $60^{\circ} \mathrm{N}$ was also classified into three categories as defined in the previous sections. As expected, Arctic SIV also showed spatial and temporal heterogeneities as SIT did (Figure 11). 

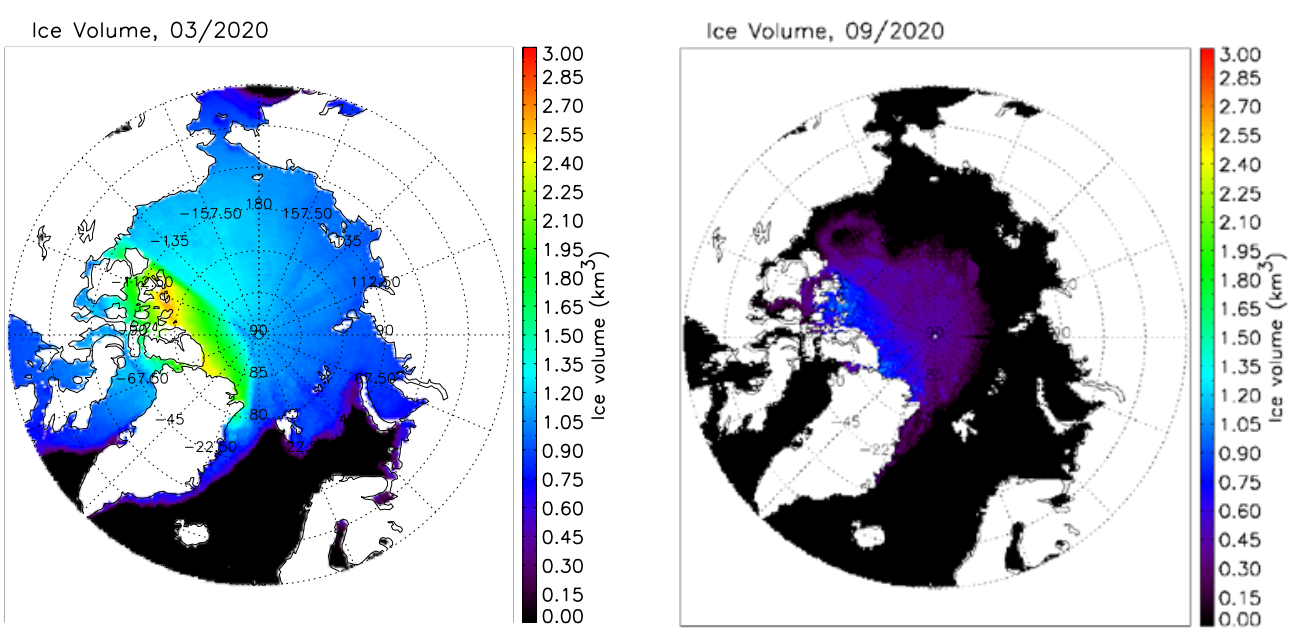

Figure 11. The spatial distributions of the Arctic monthly mean SIV in March (left) and September (right) in 2020 from this study.

The Arctic SIV trends for all months from January through December are listed in the Table 4 below.

Table 4. Monthly mean SIV trends $\left(\mathrm{km}^{3}\right.$ per year) with their uncertainties and confidence levels for AICA, PICA, and SICA.

\begin{tabular}{|c|c|c|c|c|c|c|c|c|c|}
\hline \multirow{2}{*}{ Month } & \multicolumn{3}{|c|}{ AICA } & \multicolumn{3}{|c|}{ PICA } & \multicolumn{3}{|c|}{ SICA } \\
\hline & $b$ & $U_{b}$ & $\alpha$ & $b$ & $U_{b}$ & $\alpha$ & $b$ & $U_{b}$ & $\alpha$ \\
\hline 1 & -658.1 & 19.77 & $<0.001$ & -521.5 & 18.78 & $<0.001$ & -122.7 & 13.89 & $<0.001$ \\
\hline 2 & -754.3 & 21.67 & $<0.001$ & -625.3 & 22.43 & $<0.001$ & -138.4 & 16.86 & $<0.001$ \\
\hline 3 & -859.2 & 21.63 & $<0.001$ & -715.0 & 24.20 & $<0.001$ & -138.2 & 23.48 & $<0.001$ \\
\hline 4 & -686.0 & 17.37 & $<0.001$ & -584.7 & 24.13 & $<0.001$ & -92.06 & 24.61 & 0.001 \\
\hline 5 & -454.5 & 9.546 & $<0.001$ & -437.8 & 16.68 & $<0.001$ & -9.914 & 17.39 & 0.578 \\
\hline 6 & -348.2 & 7.826 & $<0.001$ & -324.5 & 12.23 & $<0.001$ & -15.29 & 10.87 & 0.321 \\
\hline 7 & -254.5 & 5.692 & $<0.001$ & -240.2 & 8.530 & $<0.001$ & -8.392 & 5.557 & 0.147 \\
\hline 8 & -192.7 & 6.567 & $<0.001$ & -189.7 & 7.191 & $<0.001$ & -0.792 & 1.313 & 0.578 \\
\hline 9 & -170.2 & 10.05 & $<0.001$ & -168.6 & 9.944 & $<0.001$ & -0.919 & 0.431 & 0.035 \\
\hline 10 & -299.6 & 11.30 & $<0.001$ & -273.6 & 10.68 & $<0.001$ & -21.69 & 3.781 & $<0.001$ \\
\hline 11 & -408.3 & 16.07 & $<0.001$ & -351.9 & 13.37 & $<0.001$ & -55.33 & 8.346 & $<0.001$ \\
\hline 12 & -510.9 & 17.92 & $<0.001$ & -426.9 & 16.52 & $<0.001$ & -83.01 & 9.906 & $<0.001$ \\
\hline Annual & -467.7 & 10.59 & $<0.001$ & -404.2 & 13.39 & $<0.001$ & -60.34 & 10.56 & $<0.001$ \\
\hline
\end{tabular}

Arctic SIV was changing along with the changes of Arctic SIC and SIT over 1982 2020. The SIV changing rates or trends differ in spatial and temporal domains (Figure 12). 

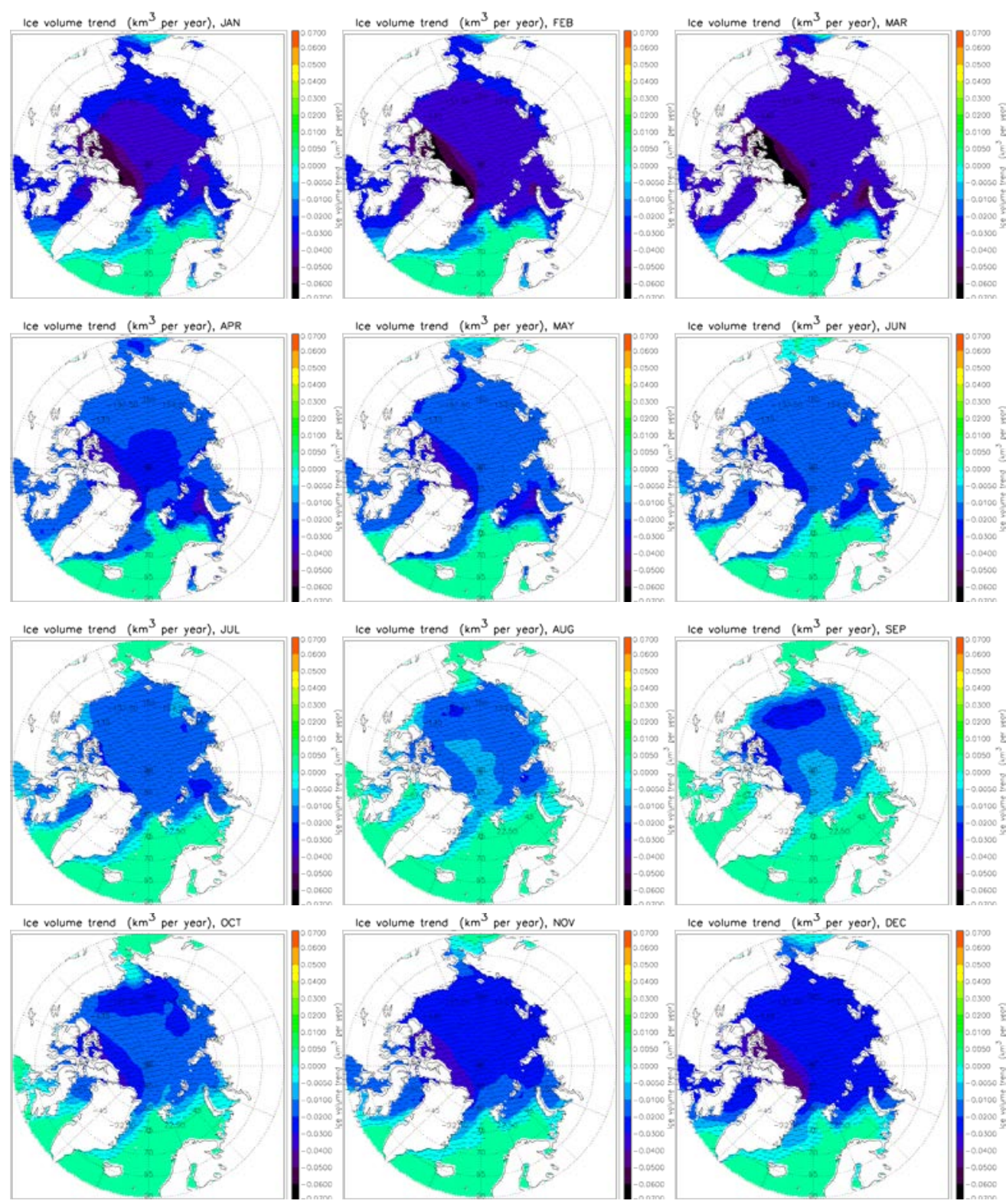

Figure 12. Spatial distributions of the Arctic monthly mean SIV trends over $1982 \sim 2020$ for the months of January through December.

The biggest declining SIV trend occurred in February and March along the Canadian Archipelagos with the changing rate of about $-0.07 \mathrm{~km}^{3}$ per year. The minimum declining SIV trends were in summer from July through September with the minimum changing rate of about $-0.010 \sim-0.005 \mathrm{~km}^{3}$ per year over the central Arctic Ocean. Figure 13 shows the Arctic SIV times series of 12 months over $1982 \sim 2020$ for AICA, PICA, and SICA, with the fitted trend lines. AICA SIV trends are also mainly controlled by PICA SIV trends in all months. 

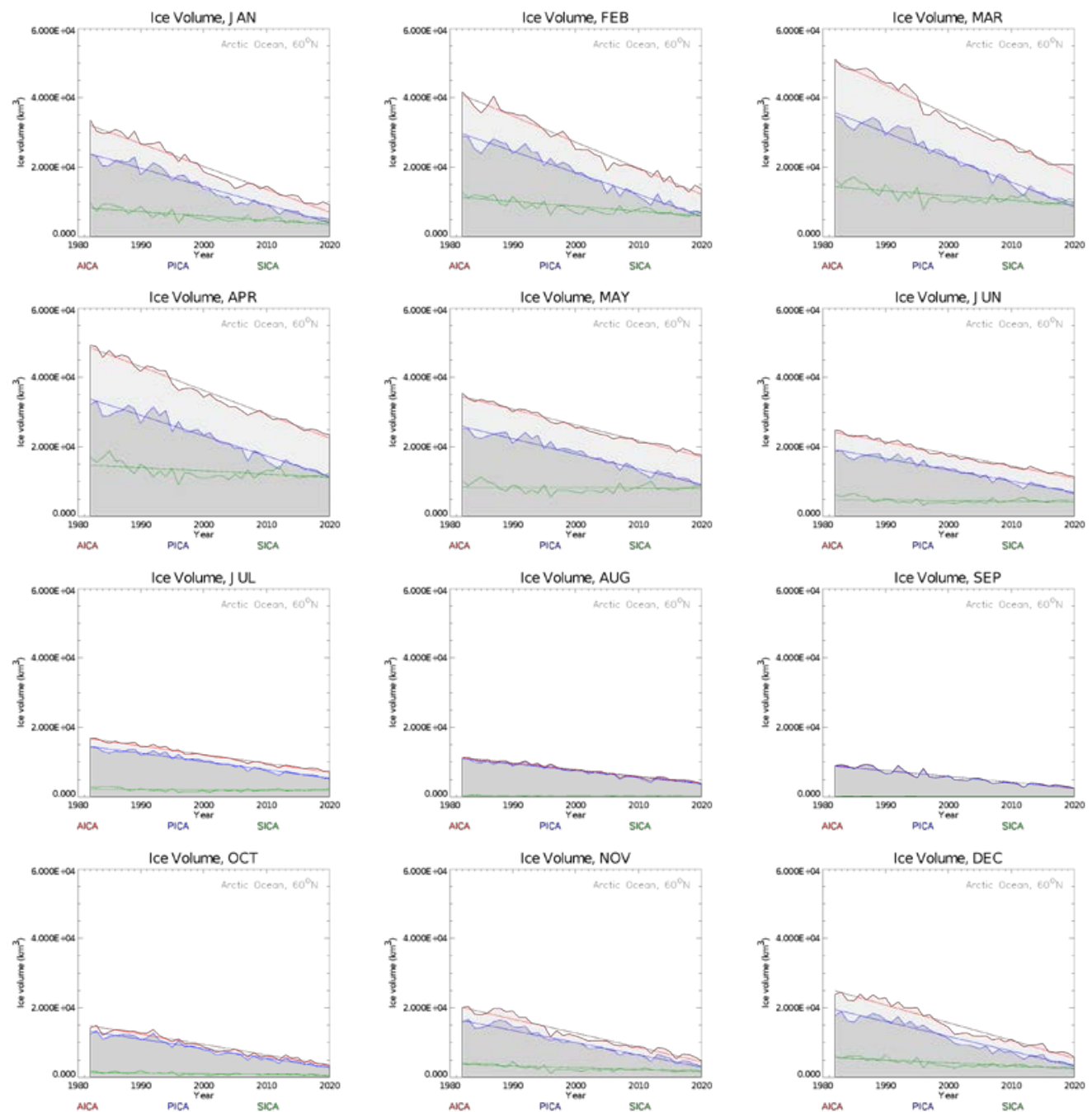

Figure 13. Arctic SIV time series for the Arctic area north of $60^{\circ} \mathrm{N}$ over $1982 \sim 2020$ for the months of January through December. PICA (blue) stands for perennial ice-covered area, SICA (green) denotes seasonal ice-covered area, and AICA (red) designates all ice (PI + SI) covered areas.

Over the period $1982 \sim 2020$, AICA SIV decreased to $20679.0 \mathrm{~km}^{3}$ in 2020 from 51216.6 $\mathrm{km}^{3}$ in 1982, resulting in about $60 \%$ decrease at the rate of $-859.2 \mathrm{~km}^{3}$ per year in March. In September, the AICA SIV declined to $2462.0 \mathrm{~km}^{3}$ in 2020 from $8931.2 \mathrm{~km}^{3}$ in 1982, resulting in about $72 \%$ decrease at the rate of $-170.2 \mathrm{~km}^{3}$ per year. Based on an annual average, AICA SIV decreased by $17284.8 \mathrm{~km}^{3}$ that is about $63 \%$ of $27590.4 \mathrm{~km}^{3}$ in 1982 , resulting in $10305.5 \mathrm{~km}^{3}$ SIV in 2020. PICA SIV and SICA SIV were declining to $5766.0 \mathrm{~km}^{3}$ and $4522.8 \mathrm{~km}^{3}$ in 2020 from $20313.0 \mathrm{~km}^{3}$ and $7271.0 \mathrm{~km}^{3}$ in 1982, respectively. In addition, the ratios of PICA SIV and SICA SIV to AICA SIV were declining in March when Arctic sea ice reaches its maximum volume over the year (Figure 14). It's about 2019 when the SICA SIV proportion started surpassing the PICA SIV proportion in March. 


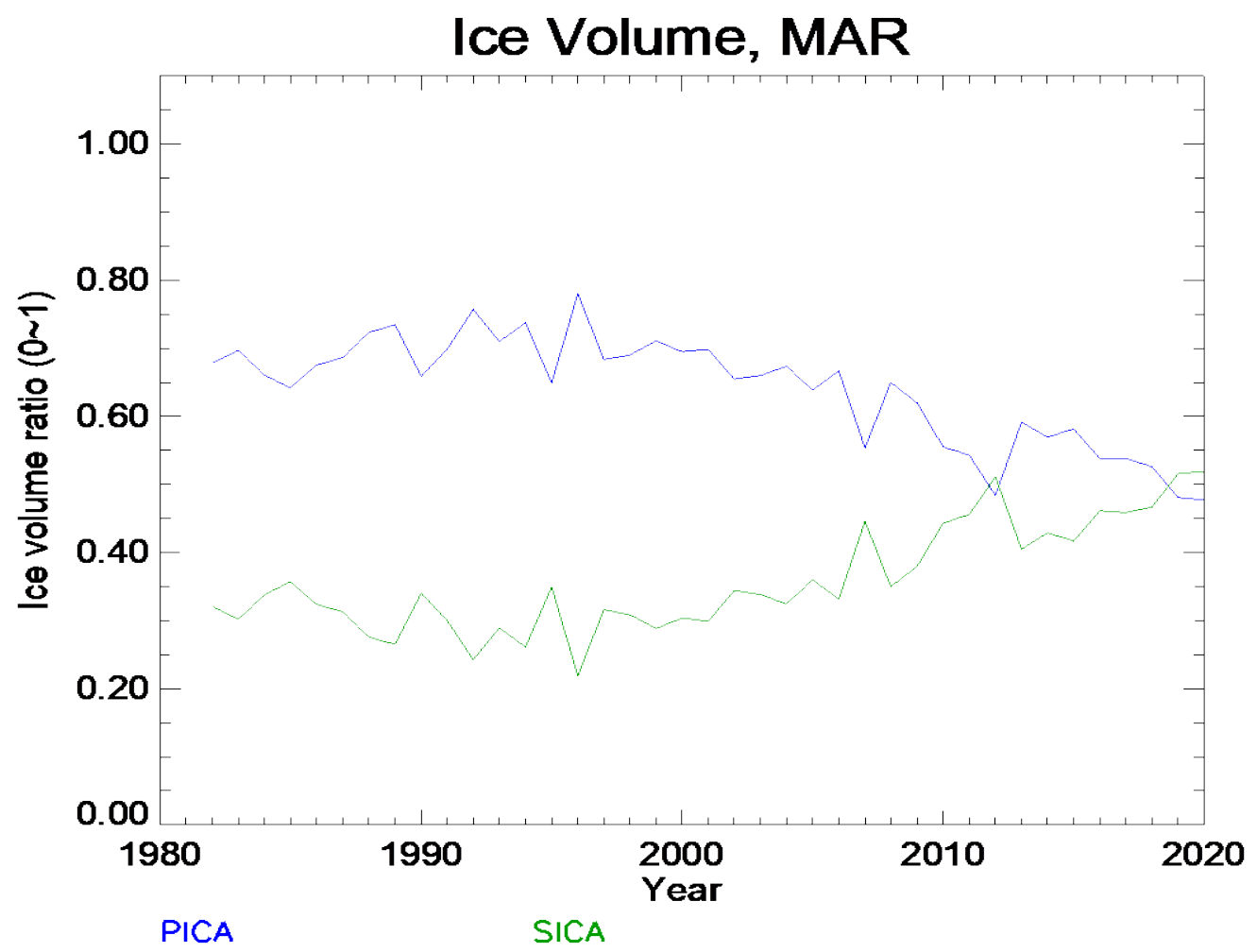

Figure 14. Ratios of PICA SIV and SICA SIV to AICA SIV in March over $1982 \sim 2020$ for the Arctic area north of $60^{\circ} \mathrm{N}$.

\section{Discussion}

Using satellite observations to study Arctic sea ice has the merits of broad spatial coverage and high temporal frequency. In this study, we used a long-term time series of Arctic sea ice properties that has been well validated and documented to study Arctic sea ice properties and changes over the period 1982 2020 for the Arctic area north of $60^{\circ} \mathrm{N}$ in each month and in the annual mean, and to estimate the time of a possible ice-free Arctic Ocean in summer. Our analyses employ a new perspective based on ice longevity: the persistence of ice in each satellite grid cell determines if that grid cell is part of the seasonal ice-covered area (SICA), where ice exists less than $95 \%$ of the days in a year, the perennial ice-covered area (PICA), where ice exists $95 \%$ or more of the days in a year, or the open water area where ice cover exists $0 \%$ of days in a year. The all ice-covered area (AICA) is defined as the sum of SICA and PICA. This approach provides a unique view of where ice is persistent and where it is disappearing, though it does not represent the true distribution of new and old ice in the traditional sense. The perspective on sea ice is important because it is the presence and persistence of ice in an area that directly influences local weather and climate, indirectly influences larger-scale climate, and impacts marine transportation and ecosystems.

We used an Arctic sea ice concentration (SIC) CDR derived with passive microwave data from the NOAA/NSIDC (https://nsidc.org/data/g02202) to investigate Arctic sea ice concentration and sea ice extent in this study. The Arctic Perennial Ice-Covered Area (PICA) and the Seasonal Ice-Covered Area (SICA) ice concentration increased in the cold season and decreased in the warm season, though the trends during the warm season were not statistically significant. On an annual average, trends in Arctic SIC for both PICA and SICA were not statistically significant. In terms of ice-covered area in the entire Arctic area north of $60^{\circ} \mathrm{N}$, or AOIF, Arctic sea ice retreated in every month and in the annual mean at the maximum rate of $-0.52 \%$ per year in September, and $-0.31 \%$ per year annually (Table 2). The AOIF declined about $20 \%$ in the last four decades on an annual average. 
The All Ice-Covered Area (AICA) sea ice extent (SIE) was reduced about $22 \%$ over the last four decades, mainly caused by the PICA SIE reduction that declined at the annual rate of $-1.105 \times 105 \mathrm{~km}^{2}$ per year. The annual increase in SICA SIE, at a rate of 2.640x104 $\mathrm{km}^{2}$ per year, does not offset the decline of the PICA SIE, resulting in a net loss of AICA SIE at the rate of $-7.871 \times 104 \mathrm{~km}^{2}$ per year. The AICA SIE in September had a minimum extent of $4.32892 \times 106 \mathrm{~km}^{2}$ in 2020 , compared to the much larger SIE of $7.63860 \times 106 \mathrm{~km}^{2}$ in 1982, resulting in about a $43 \%$ decline in the past four decades.

By using long-term APP-x climate data records and the OTIM ice thickness retrieval algorithm with the sea ice concentration climate data record from NOAA/NSIDC, Arctic sea ice thickness (SIT) and sea ice volume (SIV) can be estimated. Overall, the Arctic SIT in AICA, PICA, and SICA declined over the period 1982 2020 at the rates of $-3.24 \mathrm{~cm}$ per year, $-3.32 \mathrm{~cm}$ per year, and $-2.38 \mathrm{~cm}$ per year, respectively. The annual mean SIT decreased to $1.13 \mathrm{~m}, 1.32 \mathrm{~m}$, and $0.96 \mathrm{~m}$ in AICA, PICA, and SICA in 2020 from $2.35 \mathrm{~m}, 2.55$ $\mathrm{m}$, and $1.86 \mathrm{~m}$ in 1982, respectively. Though the minimum ice extent occurs in mid-September, the thinnest ice occurs in late September or early October as a result of newly forming ice. In 2020 the PICA SIT in September, October, and November are all approximately $0.70 \mathrm{~m}$, while in 1982 the PICA SIT is $1.38 \mathrm{~m}, 1.58 \mathrm{~m}$, and $1.96 \mathrm{~m}$ in those three months, respectively. This implies an extended summertime ice condition in the Arctic over the study period.

On an annual average, Arctic sea ice volume including seasonal and perennial ice north of $60^{\circ} \mathrm{N}$ decreased by about $62 \%$ over the last four decades at the rate of $-467.7 \mathrm{~km}^{3}$ per year. This was mainly caused by the loss of perennial ice, which decreased by about $72 \%$ at the rate of $-404.2 \mathrm{~km}^{3}$ per year. The seasonal ice volume decreased about $38 \%$ at the rate of $-60.34 \mathrm{~km}^{3}$ per year. In terms of the absolute magnitude, the largest decrease in ice volume was in March at a rate of $-859.2 \mathrm{~km}^{3}$ per year. The lowest rate of decrease was in September at the rate of $-170.2 \mathrm{~km}^{3}$ per year (Table 4 ).

Based on those trends, the Arctic Ocean could become ice free in September in the 2061 2064 timeframe if the current trends continue. Changes in other components of the climate system and climate feedbacks could alter these trends, of course. If we use three standard deviations as reasonable uncertainties in the trends, the earliest years when the Arctic Ocean could experience an ice-free September would be in the 2044-2048 timeframe, with the latest being around 2088-90.

Author Contributions: Xuanji Wang conceived the idea of this study, generated the Arctic sea ice properties dataset, analyzed the results, and wrote the manuscript. Jeffrey Key provided valuable guidance on the work and editing of the manuscript. Yinghui Liu and Richard Dworak provided the APP data and helped in manuscript editing. All authors discussed the results and assisted in revising the manuscript.

Funding: Please add: This work was supported by the National Oceanic and Atmospheric Administration (NOAA) National Centers for Environmental Information (NCEI) Climate Data Records Program (grant no. 1332KP19FNEEN0003 to the University of Wisconsin-Madison) and the Joint Polar Satellite System (JPSS) Program Office (grant no. NA20NES4320003 to the University of Wisconsin).

Data Availability Statement: All data needed to make the results in the paper are present in the papers or the Supplementary Materials. The NOAA/NSIDC Passive Microwave Sea Ice Concentration (SIC) CDR is available at https://nsidc.org/data/g02202. The APP and APP-x datasets are available at https://nsidc.org/data/nsidc-0669.

Acknowledgments: We thank the National Snow and Ice Data Center (NSIDC) providing the ice concentration data. Our thanks also go to NASA-MERRA project for the reanalysis global profile data set.

Conflicts of Interest: The authors declare no conflict of interest. 


\section{References}

1. Walsh, J.E.; Overland, J.E.; Groisman, P.Y.; Rudolf, B. Ongoing Climate Change in the Arctic. AMBIO 2012, 40, 6-16, doi:10.1007/s13280-011-0211-z.

2. Jansen, E.; Christensen, J.H.; Dokken, T.; et al. Past perspectives on the present era of abrupt Arctic climate change. Nat. Clim. Chang. 2020, 10, 714-721, doi:10.1038/s41558-020-0860-7.

3. Box, J.E.; Colgan, W.T.; Christensen, T.R.; et al. Key indicators of Arctic climate change: 1971-2017. Environ. Res. Lett. 2019, 14 045010 .

4. Cavalieri, D.J.; Parkinson, C.L.; Vinnikov, K.Y. 30-Year satellite reveals contrasting Arctic and Antarctic decadal sea ice variability. Geophys. Res. Lett. 2003, 30, 18, 1970, doi: 10.1029/2003GL018031.

5. Parkinson, C. L.; Comiso, J. C. 2013: On the 2012 record low Arctic sea ice cover: Combined impact of preconditioning and an August storm. Geophys. Res. Lett. 2013, 40, 1356-1361, doi:10.1002/grl.50349.

6. Wang, X.; Key, J.; Liu, Y.; Fowler, C.; Maslanik, J.; Tschudi, M. Arctic Climate Variability and Trends from Satellite Observations, Advances in Meteorology 2012, 2012, Article ID 505613, 22 pages, doi:10.1155/2012/505613.

7. Liu, Y.; Key, J. R., Wang, X.; Tschudi, M. Multidecadal Arctic sea ice thickness and volume derived from ice age. The Cryosphere 2020, 14, 1325-1345, doi:10.5194/tc-14-1325-2020.

8. Kwok, R; Rothrock, D.A. Decline in Arctic sea ice thickness from submarine and ICESat. Geophys. Res. Lett. 2009, 36, L15501, doi:10.1029/2009GL039035.

9. Zhang, J.; Lindsay, R.; Schweiger, A.; Rigor, I. Recent changes in the dynamic properties of declining Arctic sea ice: A model study. Geophys. Res. Lett. 2012, 39, L20503, doi:10.1029/2012GL053545.

10. Meier, W.N.; Hovelsrud, G.K.; Oort, B.E.; et al. 2014: Arctic sea ice in transformation: A review of recent observed changes and impacts on biology and human activity. Rev. Geophys. 2014, 52, 185- 217, doi:10.1002/2013RG000431.

11. Lindsay, R.; Schweiger, A. Arctic sea ice thickness loss determined using subsurface, aircraft, and satellite observations. The Cryosphere 2015, 9, 269-283, doi:10.5194/tc-9-269-2015.

12. Hassol, S. Arctic Climate Impact Assessment. Cambridge University Press: 40 West 20 $0^{\text {th }}$ Street, New York, NY 10011-4211, USA, 2005; ; pp. 1042.

13. Serreze, M. C.; Holland, M.M.; Stroeve, J. Perspectives on the Arctic's Shrinking Sea-ice Cover. Science 2007, 315, 5818, 15331536. doi:10.1126/science.1139426.

14. Zhang, J.; Lindsay, R.; Steele, M.; Schweiger, A. What drove the dramatic retreat of arctic sea ice during summer 2007?. Geophys. Res. Lett. 2008, 35, L11505, doi:10.1029/2008GL034005.

15. Wang, X.; Key, J.R. Recent Trends in Arctic Surface, Cloud, and Radiation Properties from Space. Science 2003, 299, 1725-1728, doi:10.1126/science.1078065.

16. Nghiem, S.V.; Rigor, I.G.; Perovich, D.K.; et al. Rapid reduction of Arctic perennial sea ice. The Cryosphere 2007, 34, L19504, doi:10.1029/2007GL031138.

17. Kwok, R. Arctic sea ice thickness, volume, and multiyear ice coverage: losses and coupled variability (1958-2018). Environ. Res. Lett. 2018, 13, 105005.

18. Maslanik, J.A.; Fowler, C.; Stroeve, J.; Drobot, S.; Zwally, J.; Yi, D.; Emery, W. A younger, thinner Arctic ice cover: Increased potential for rapid, extensive sea-ice loss. Geophys. Res. Lett. 2007, 34, L24501, doi:10.1029/2007GL032043.

19. Perovich, D.K.; Light, B.; Eicken, H.; et al. Increasing solar heating of the Arctic Ocean and adjacent seas 1979-2005: Attribution and role in the ice-albedo feedback. Geophys. Res. Lett. 2007, 34, L9505, doi:10.1029/2007GL031480.

20. Perovich, D.K.; Richter-Menge, J.A.; Jones, K.F.; et al. Sunlight, water, and ice: Extreme Arctic sea ice melt during the summer of 2007. Geophys. Res. Lett. 2008, 35, L11501, doi:10.1029/2008GL034007.

21. Polyakov I.V.; Timokhov, LA.; Alexeev V.A.; et al. Arctic Ocea n warming contributes to reduced polar ice cap. Journal of Physical Oceanography 2010, 40, 12, 2743-2756.

22. Kay, J.E.; Gettelman, A. Cloud influence on and response to seasonal Arctic sea ice loss. Journal of Geophysical Research 2009, 114, D18204, doi:10.1029/2009JD011773.

23. Liu, Y.; Key, J.R.; Liu, Z.; Wang, X.; Vavrus, S.J. A cloudier Arctic expected with diminishing sea ice. Geophys. Res. Lett. 2012, 39, L05705, doi:10.1029/2012GL051251.

24. Taylor, P.C.; Kato, S.; Xu, K.-M.; Cai, M. C.J.D. Covariance between Arctic sea ice and clouds within atmospheric state regimes at the satellite footprint level, J. Geophys. Res. Atmos. 2015, 120, 12656-12678, doi:10.1002/2015JD023520.

25. Stuecker, M.F.; Bitz, C.M.; Armour, K.C.; et al. Polar amplification dominated by local forcing and feedbacks. Nature Clim Change 2018, 8, 1076-1081, doi:10.1038/s41558-018-0339-y.

26. Dai, A.; Luo, D.; Song, M. et al. Arctic amplification is caused by sea-ice loss under increasing CO2. Nat. Commun. 2019, 10, 121 doi:10.1038/s41467-018-07954-9.

27. Zhang X. Sensitivity of arctic summer sea ice coverage to global warming forcing: towards reducing uncertainty in arctic climate change projections. Tellus A: Dynamic Meteorology and Oceanography 2010, 62, 3, 220-227.

28. Notz D.; Stroeve J. Observed Arctic sea-ice loss directly follows anthropogenic CO2 emission. Science 2016, 354, 6313, 747-750.

29. Davy, R.; Outten, S. The arctic surface climate in CMIP6: Status and developments since CMIP5. Journal of Climate 2020, 33, 8047-8068, doi:10.1175/JCLI-D-19-0990.1.

30. Notz, D.; Community, S. Arctic Sea Ice in CMIP6. Geophysical Research Letters 2020, 47, doi:10.1029/2019GL086749. 
31. Lindsay, R.W.; Zhang, J.; Schweiger, A.; Steele, M.; Stern, H. Arctic Sea Ice Retreat in 2007 Follows Thinning Trend. Journal of Climate 2009, 22, 1, 165-176, doi:10.1175/2008JCLI2521.1.

32. Lindsay, R.W.; Schweiger, A. Arctic sea ice thickness loss determined using subsurface, aircraft, and satellite observations. The Cryosphere 2015, 9, 269-283, 2015, doi:10.5194/tc-9-269-2015.

33. Schweiger, A.J.; Wood, K.R.; Zhang, J. Arctic Sea Ice Volume Variability over 1901-2010: A Model-Based Reconstruction. Journal of Climate 2019, 32, 4731-4752, doi:10.1175/jcli-d-19-0008.1.

34. Jansen, E.; Christensen, J.H.; Dokken, T.; et al. Past perspectives on the present era of abrupt Arctic climate change. Nat. Clim. Chang. 2020, 10, 714-721, doi:10.1038/s41558-020-0860-7.

35. Stroeve, J.; Barrett, A.; Serreze, M.; Schweiger, A. Using records from submarine, aircraft and satellites to evaluate climate model simulations of Arctic sea ice thickness. The Cryosphere 2014, 8, 1839-1854, doi:10.5194/tc-8-1839-2014.

36. Bi, H.; et al. Arctic Sea Ice Volume Changes in Terms of Age as Revealed From Satellite Observations. IEEE Journal of Selected Topics in Applied Earth Observations and Remote Sensing 2018, 11, 7, 2223-2237, doi:10.1109/JSTARS.2018.2823735.

37. Liu, Y.; Key, J. R.; Wang, X.; Tschudi, M. Multidecadal Arctic sea ice thickness and volume derived from ice age. The Cryosphere 2020, 14, 1325-1345, doi:10.5194/tc-14-1325-2020.

38. Key, J.R.; Wang, X.; Liu, Y.; Dworak, R.; Letterly, A. The AVHRR Polar Pathfinder Climate Data Records. Remote Sens. 2016, 8, 3, 167, doi:10.3390/rs8030167.

39. Wang, X.; Key, J.R.; Liu, Y. A thermodynamic model for estimating sea and lake ice thickness with optical satellite data. Journal of Geophysical Research: Oceans 2010, 115, doi:10.1029/2009JC005857.

40. Key, J. R.; Wang, X.; Stroeve, J.; Fowler, C. Estimating the cloudy-sky albedo of sea ice and snow from space. J. Geophys. Res. 2001, 106(D12), 12,489-12497.

41. Key, J. R.; Yang, P.; Baum, B.A.; Nasin, S.L. Parameterization of shortwave ice cloud optical properties for various particle habits. J. Geophys. Res. 2002, 107 (D13), 4181, doi:10.1029/2001JD000742.

42. Key, J.R.; Schweiger, A.J. Tools for atmospheric radiative transfer: Streamer and FluxNet. Computer E Geosciences 1998, 24, 5, 443-451.

43. Maslanik, J.A.; Key, J.R.; Fowler, C.W.; Nguyen, T.; Wang, X. Spatial and Temporal Variability of Satellite-derived Cloud and Surface Characteristics During FIRE-ACE. J. Geophys. Res. 2001, 106(D14), 15,233-15, 249.

44. Stroeve, J.; Box, J.; Fowler, C.; Haran, T.; Key, J. Intercomparison Between in situ and AVHRR Polar Pathfinder-derived Surface Albedo over Greenland. Remote Sensing of the Environment 2001, 75, 3, 360-374.

45. Key, J.; Intrieri, J. Cloud particle phase determination with the AVHRR. J. Appl. Metorol. 2000, 36, 10, $1797-1805$.

46. Pavolonis, M. J.; Key, J.R.; Wang, X. Antarctic cloud radiative forcing at the surface estimated from the ISCCP D2 and AVHRR Polar Pathfinder data sets, 1985-1993. IEEE International Geoscience and Remote Sensing Symposium 2002, 6, 3237-3239, doi:10.1109/IGARSS.2002.1027141.

47. Wang, X.; Key, J.R. Arctic Surface, Cloud, and Radiation Properties Based on the AVHRR Polar Pathfinder Data Set. Part I: Spatial and Temporal Characteristics. J. of Climate 2005, 18, 14, 2558-2574.

48. Wang, X.; Key, J.R.; Kwok, R.; Zhang, J. Comparison of Arctic sea ice thickness from satellites, aircraft, and PIOMAS data. Remote Sensing 2016, 8, 9, doi:10.3390/rs8090713. Reprint \# 7738.

49. Tschudi, M.A.; Meier, W.N.; Stewart, J.S. An enhancement to sea ice motion and age products at the National Snow and Ice Data Center (NSIDC). The Cryosphere 2020, 14, 1519-1536, doi:10.5194/tc-14-1519-2020.

50. Mann, H.B. Non-parametric tests against trend. Econometrica 1945, 13, 163-171.

51. Kendall, M.G. Rank Correlation Methods, 4th ed.; Charles Griffin, London, GB, 1970.

52. Gilbert, R.O. Statistical Methods for Environmental Pollution Monitoring; John Wiley \& Sons, NY, USA, 1987.

53. Sen, P.K. 1968: Estimates of the Regression Coefficient Based on Kendall's Tau. Journal of the American Statistical Association 1968, 63, 324, 1379-1389, doi:10.1080/01621459.1968.10480934.

54. Yu, P. S.; Yang, T.C.; Wu, C.K. 2002: Impact of Climate Change on Water Resources in Southern Taiwan. Journal of Hydrology 2002, 260, 161-175.

55. Lettenmaier, D.P.; Wood, E.F.; Wallis, J.R. Hydroclimatological Trends in the Continental United States 1948-1988. Journal of Climate, 1994, 7, 4, 586-607.

56. Burn, H.S.; Elnur, M.A.H. Detection of Hydrologic Trends and Variability. Journal of Hydrology 2002, 255, 107-122. 